\title{
Deformation capacity evaluation for flat slab seismic design
}

\author{
A. Muttoni ${ }^{1}$ - D. Coronelli ${ }^{2} \cdot$ M. Lamperti Tornaghi ${ }^{3}$ D $\cdot$ L. Martinelli ${ }^{2} \cdot$ I. R. Pascu ${ }^{4}$.

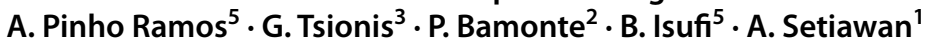

Received: 2 February 2021 / Accepted: 29 November 2021 / Published online: 28 January 2022 (c) The Author(s) 2021

\begin{abstract}
In flat-slab frames, which are typically designed as secondary seismic structures, the shear failure of the slab around the column (punching failure) is typically the governing failure mode which limits the deformation capacity and can potentially lead to a progressive collapse of the structure. Existing rules to predict the capacity of flat slab frames to resist imposed lateral displacements without losing the capability to bear gravity loads have been derived empirically from the results of cyclic tests on thin members. These rules account explicitly only for the ratio between acting gravity loads and resistance against concentric punching shear (so-called Gravity Shear Ratio). Recent rational models to estimate the deformation capacity of flat slabs show that other parameters can play a major role and predict a significant size effect (reduced deformation for thick slabs). In this paper, a closed-form expression to predict the deformation capacity of internal slab-column connections as a function of the main parameters is derived from the same model that has been used to develop the punching shear formulae for the second generation of Eurocode 2 for concrete structures. This expression is compared to an existing database of isolated internal slab-column connections showing fine accuracy and allowing to resolve the shortcomings of existing rules. In addition, the results of a testing programme on a full-scale flat-slab frame with two stories and 12 columns are described. The differences between measured interstorey drifts and local slab rotations influencing their capacity to resist shear forces are presented and discussed. With respect to the observed deformation capacities, similar values are obtained as in the isolated specimens and the predictions are confirmed for the internal columns, but significant differences are observed between internal, edge and corner slab-column connections. The effects of punching shear reinforcement and of integrity reinforcement (required according to Eurocode 2 to prevent progressive collapse after punching) are also discussed.
\end{abstract}

Keywords Eurocode $8 \cdot$ Eurocode 2 - Flat plate $\cdot$ Full-scale testing $\cdot$ Gravity shear ratio . Slab rotation

Prof. Ion Radu Pascu deceased on June 10 ${ }^{\text {th }}, 2021$.

M. Lamperti Tornaghi

marco.lamperti-tornaghi@ec.europa.eu

Extended author information available on the last page of the article 


\section{List of symbols}

$b_{0.5} \quad$ Length of the control perimeter for punching shear verification located at a distance $0.5 d$ from the column edge

$c \quad$ Column size (width of square columns)

$d \quad$ Effective depth of a cross section (distance between the extreme compression fibre and the centroid of longitudinal tension reinforcement)

$d_{g} \quad$ Maximum aggregate size

$d_{r} \quad$ Interstorey drift

$f_{c} \quad$ Compressive concrete strength

$f_{y} \quad$ Yield strength of reinforcement

$g_{k} \quad$ Characteristic value of the permanent load

GSR Gravity Shear Ratio, $V_{E d} / V_{R d, c}$

$h_{s} \quad$ Storey height

$L \quad$ Slab span (distance between axes of supports)

$m_{E d} \quad$ Design value of the moment in the slab per unit width

$M_{E d} \quad$ Design value of the moment transferred from the column to the slab ("unbalanced moment")

$m_{R d} \quad$ Design value of the flexural resistance of the slab per unit width

$q_{k} \quad$ Characteristic value of the variable load

$V_{E d} \quad$ Design value of the acting vertical shear force on the slab-column connection

$V_{R d, c} \quad$ Design value of the centric punching shear resistance of a slab without shear reinforcement

$\beta_{e} \quad$ Coefficient accounting for the concentration of shear forces along the control perimeter

$\gamma \quad$ Partial safety factor for concrete

$\gamma_{G} \quad$ Partial factor for permanent actions

$\gamma_{Q} \quad$ Partial factor for variable actions

$\gamma_{V} \quad$ Partial safety factor for shear

$\rho_{s a g} \quad$ Ratio of sagging reinforcement (top slab reinforcement) in the column region

$\rho_{\text {hog }} \quad$ Ratio of hogging reinforcement (bottom slab reinforcement) in the column region

$\phi \quad$ Diameter of reinforcement bar

$\psi_{2} \quad$ Combination factor applied to a variable action to determine its quasi-permanent value

$\psi_{c o l} \quad$ Contribution of the column deformation to the interstorey drift ratio

$\psi_{i s d} \quad$ Interstorey drift ratio (corresponding to $d_{r} / h_{s}$ )

$\psi_{i s d, R} \quad$ Interstorey drift ratio at failure (unbalanced moment corresponding to $80 \%$ of the peak value)

$\psi_{\text {isd,ave }}$ Average drift ratio (displacement of the top floor divided by the building height )

$\psi_{\text {slab }} \quad$ Slab rotation at column axis

$\psi_{\text {slab,E }} \quad$ Slab rotation imposed by the deformation of the primary seismic structure

$\psi_{\text {slab, },} \quad$ Rotation capacity of the slab (slab rotation at column axis for $80 \%$ of maximum unbalanced moment)

@ Spacing of slab reinforcement 


\section{Introduction}

Flat slab buildings for commercial, office and residential use are a common solution in many countries. Extensive studies of their behaviour under gravity and seismic actions have been carried out in North America starting from the 1970s whereas European research developed more recently. Nevertheless, the current Eurocode 8 (the European code for seismic structural design EN 1998-1:2004 (CEN 2004a), called in the following EC8:2004), and particularly Sect. 5 of part 1 on concrete buildings, does not provide specific provisions for this type of structures.

With the widespread and growing use of these structures in countries with relevant seismic actions, code and research developments have been advocated in the European research community (Spence et al. 2007; Fardis 2009). For instance, Pinto et al. (2007) indicate flat slab design as one of the topics needing pre-normative research for the next generation of EN 1998.

EC8:2004 contains general provisions for primary and secondary seismic elements, similar provisions are also contained in the latest draft of the second generation of EC8 (CEN/TC 250/SC 8 2020). Primary seismic members are considered as part of the structural system that resists the seismic action. They are modelled in the global analysis and are fully designed and detailed for earthquake resistance. Secondary seismic members are not considered in the design of the seismic resisting system and their strength and stiffness against seismic actions is neglected. EC8:2004 (CEN 2004a) explicitly states that primary flat plate frames are "not fully covered" (clause 5.1.1(2)). Following these definitions, Fardis (2009) proposes the design of flat plate frames as secondary systems, based on resistance verifications for the structure bearing gravity loads at the deformations imposed by the design earthquake. In addition, the latest draft of EC8 for buildings (CEN/TC 250/SC 8 2020) contains provisions for flat slabs as primary seismic members, but no explicit indication is given how to verify flat slabs designed as secondary seismic member accounting for the imposed deformations.

An approach to verify slab-column connections with respect to their deformation capacity is proposed in this paper. Since current provisions for punching in Eurocode 2 are force-based, they do not explicitly cover punching under lateral loading as a deformation-related failure mode. Tests on slab-column specimens have shown that the drift capacity is correlated with the gravity shear ratio, i.e. the ratio between the applied gravity load effects and the concentric punching shear resistance (Ramos et al. 2017). This is confirmed by the results of a mechanical model predicting the interstorey drift capacity of a full flat slab (Drakatos et al. 2018), in accordance with the recent developments for the punching shear resistance implemented in the draft for the second generation of Eurocode 2. According to this model, the deformation capacity depends not only on the gravity shear ratio, but also on the slab thickness (size effect), the column size, the amount of flexural reinforcement and the slab slenderness. These theoretical results are used in this paper to develop a closed-form relationship accounting for all these effects for use in seismic design. 
To verify the deformation capacity of flat slab frames under seismic actions, a fullscale two-storey structure with $2 \times 3$ bays has been tested at the ELSA Laboratory at JRC in Ispra, Italy, with the purpose of providing the basis for improved design rules and code development (Coronelli et al. 2021). The deformation capacities observed in the tested structure are presented in this paper and are compared to the proposed model.

\section{Background}

Extensive research has been carried out on flat slab seismic response over the past 50 years in North America. Seminal works include Hawkins et al. (1974), Morrison et al. (1983), Pan and Moehle (1989), Megally and Ghali (2000), amongst others. This research has led to the development of code provisions (ACI 318 2019) and design rules (Joint ACI-ASCE Committee 421 2010) encompassing performance-based prescriptions for the ultimate rotation capacity of slab-column connections (Hueste et al. 2007; Zhou and Hueste 2017). It should be noted, however, that the database on which the aforementioned provisions are based mainly consists of small-scale tests on isolated internal slab-column connections.

The progress of European design and codes relies on an improved understanding of the experimental behaviour and on the development of suitable models for use in design. Design codes to date in Europe have been reluctant to include detailed deformation capacity criteria for slab-column connections, in contrast to the North American codes.

Experimental work on horizontal cyclic loading of slab-column connections does exist in Europe, although to a lesser extent compared to North America, and it is more recent. One of the first works was conducted by Farhey et al. (1993), who carried out experimental tests for cyclic loading on slab column connections, and subsequent tests on specimens repaired using steel plates (Farhey et al. 1995). Later, several tests were carried out in Portugal to study slab-column connections with and without shear reinforcement (Almeida et al. 2016, 2020a, b; Isufi et al. 2019) and various longitudinal reinforcement ratios (Isufi et al. 2021). Drakatos et al. (2016) tested internal slab-column connections in full scale under monotonic and cyclic imposed rotations, investigating the drift capacity for different types of loading, gravity shear ratios and reinforcement ratios. Interior and exterior waffle flat slab-column connections under lateral loading have been studied in Spain under cyclic loading (Benavent-Climent et al. 2008, 2009) as well as through shake table tests of a half scale one bay floor (Benavent-Climent et al. 2016; Benavent-Climent et al. 2019).

A state of the art of flat slab floor and frames studies has been presented by Coronelli et al. (2020). The results reveal that ultimate drift ratios ranging between 3 and $6 \%$ were reached for gravity shear ratios corresponding to seismic design situations. All but one of the tests examined were carried out on scaled specimens. Coelho et al. (2004) tested a full scale, three storey waffle-slab structure, with one bay on each direction at the EC JRC in Ispra. The results showed deformation capacities reaching between 1.75 and $5.0 \%$. An accumulation of torsional and flexural damage in the edge connections and the high flexibility of the structural system has been observed.

On the basis of the overview above (covering experimental work worldwide), several topics need further research developments. For instance, tests of full-size slab-column connections are not numerous and tests on edge and corner connection with cyclic 


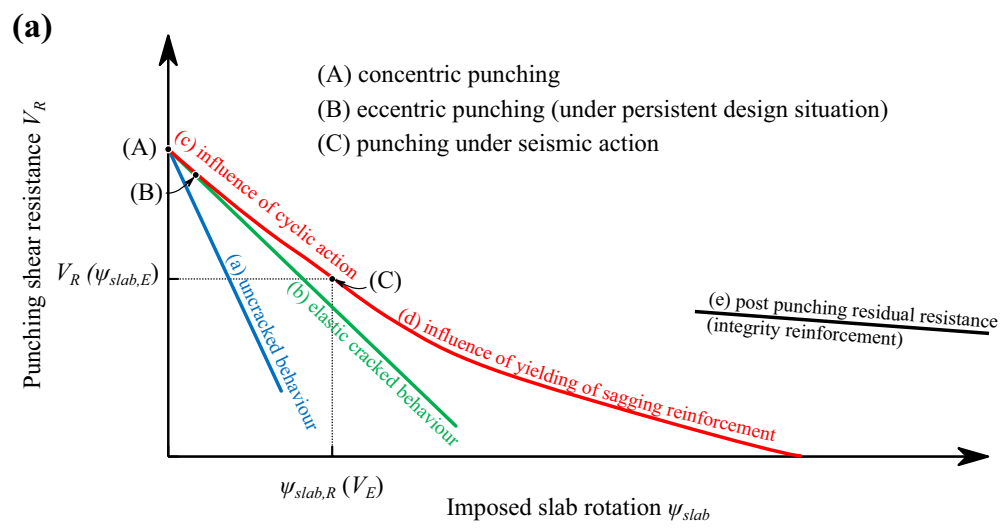

(b)

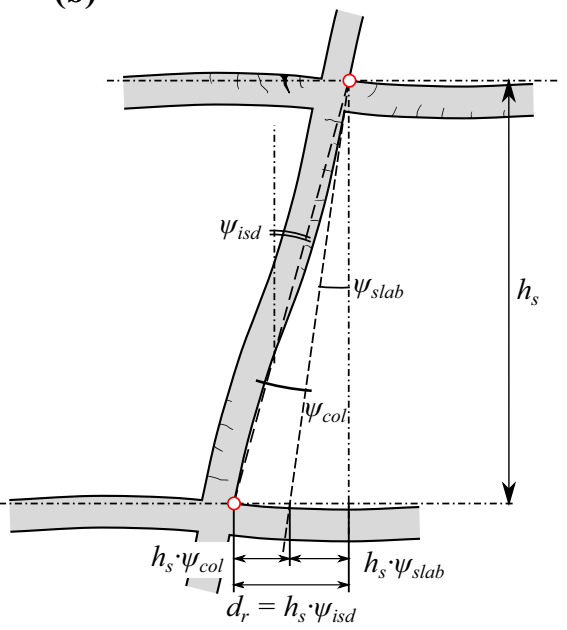

(c)

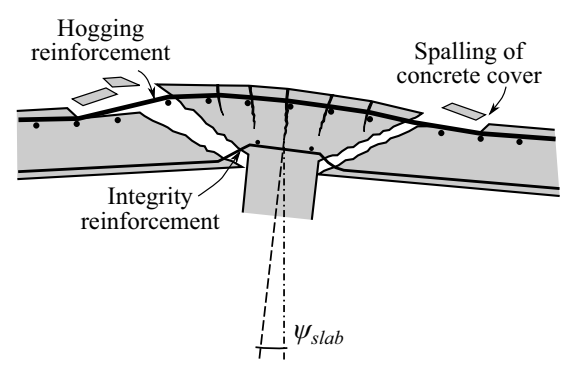

Fig. 1 a Punching shear resistance as a function of the rotation $\psi_{s l a b}$ imposed to the slab-column connection; b relationship between interstorey drift $d_{r}$, column rotation $\psi_{c o l}$ and contribution of the slab $\psi_{\text {slab }}$ to the interstorey drift ratio $\psi_{i s d}$ and $\mathbf{c}$ situation after punching

loading are quite limited. These research gaps have motivated the SlabSTRESS research programme (Coronelli et al. 2021), in which a multi-storey and multi-bay flat slab frame with realistic dimensions was tested and analysed with a focus on exploring the deformation capacity of slab-column connections.

Besides experimental work, theoretical, analytical and numerical works can be useful in filling the research gaps and paving the way forward to an improvement of the design codes. Ramos et al. (2017) proposed an empirically based expression to predict the ultimate rotation as a function of gravity shear ratio calculated using Eurocode 2 (2004). Mechanical models allowing to predict the rotation capacity of internal slabcolumn connections of flat slabs have been proposed recently by Drakatos et al. (2018), Setiawan et al. (2019) and by Broms (2020).

The model of Drakatos et al. (2018) is an extension of the Critical Shear Crack Theory (CSCT) (Muttoni 2008) for lateral seismic loading conditions. Instead of considering 
axis-symmetric conditions as in the case of gravity loading for equal spans in both directions, the slab-rotations are assumed to vary tangentially following a sinusoidal law as a function of the angle of the slab sector with respect to the direction of lateral loading. Failure criteria based on CSCT for both monotonic and cyclic loading are proposed and compared to experiments. Setiawan et al. (2019) and Broms (2020) have proposed simpler alternatives based on CSCT with a reduced basic control perimeter and a strut-and-tie model, respectively. These simplified approaches as well as the model of Drakatos et al. (2018) show the importance of testing specimens with realistic thickness, and they point out shortcomings in the North American approach as well as the need for further research (although the punching provision for gravity loading in ACI 318-19 now considers size effect as it was in European standards since decades, the seismic provision for punching still neglect this effect).

A development of these works in a closed-form formulation to evaluate the deformation capacity, based on recent proposals for European codes, offers a convenient form for design that will be presented in the following section.

\section{Verification of deformation capacity of flat slabs}

\subsection{Definition of deformation capacity}

The prescriptive provision of EC8:2004 is that secondary members shall bear the gravity loads with the concurrent deformations due to the design earthquake and in accordance with the deformability of the primary system. In a linear analysis, these deformations can be obtained by multiplying the displacements obtained in the structural analysis by the behaviour factor, $q$.

As shown in Fig. 1b, the interstorey drift $d_{r}$ typically comprises the deformation of the slab (rotation $\psi_{\text {slab }}$ ) and of the column (rotation $\psi_{\text {col }}$ ) (Drakatos et al. 2018):

$$
d_{r}=\left(\psi_{s l a b}+\psi_{c o l}\right) \cdot h_{s}
$$

where $h_{s}$ is the storey height. Since, for non-slender columns, the column rotation $\psi_{c o l}$ is often small compared to the slab rotation $\psi_{\text {slab }}$, the latter is often approximated with the interstorey drift ratio $\psi_{i s d}=d_{r} / h_{s}\left(\psi_{\text {slab }} \approx \psi_{\text {isd }}\right)$.

It has to be noted that the case shown in Fig. $1 \mathrm{~b}$ refers to a situation with similar rotations $\psi_{\text {slab }}$ of both slabs at the top and at the bottom of the column. In case of vertical discontinuities (in terms of columns and slabs), different relationships between the local rotation $\psi_{\text {slab }}$ and the interstorey drift ratio $\psi_{i s d}$ can be observed. The cases of the $1^{\text {st }}$ floor slab (where $\psi_{\text {slab }}$ can be larger than $\psi_{i s d}$ due to the presence of a stiff foundation) and the top slab (where $\psi_{\text {slab }}$ can be significantly smaller than $\psi_{i s d}$ ) will be discussed in Sect. 5.

As shown in Fig. 1a, the concurrent imposed deformation due to seismic action (defined here as $\psi_{\text {slab,E }}$ ) reduces the punching shear resistance $V_{R}$. This is mainly due to the moment $M_{E d}$ transferred from the column to the slab (so-called unbalanced moment) as a consequence of the imposed rotation $\psi_{\text {slab }}$, but also to the detrimental effect of the cyclic action as shown by Drakatos et al. (2016) and Almeida et al. (2016) by comparing cyclic and monotonic tests on slab-column connections.

For a practical design of the secondary system, the calculation of internal vertical shear forces in the slab, $V_{E d}$, and column moments, $M_{E d}$ can be conducted for gravity loads and lateral deformations imposed by the design earthquake with cracked flexural and shear stiffness. With these assumptions, $M_{E d}$ is linearly related to $\psi_{E d}$ and since the interaction between the punching shear resistance $V_{R d}$ and the unbalanced moment $M_{E d}$ can also be 
assumed as linear, the relationship (b) in Fig. 1a becomes also linear. Compared to this assumption, the actual behaviour of flat slabs is characterized by an increased deformation capacity (curves (c) and (d) in Fig. 1a) due to the increased deformation related to cyclic action and to potential yielding of hogging and sagging slab reinforcement (top reinforcement placed in the column region to carry the negative moments due to gravity loads and bottom flexural reinforcements in the slab which is usually distributed over the whole slab surface). This means that the verification assuming cracked elastic stiffness in the analysis (line (b) in Fig. 1a) can lead to overly conservative internal moments and forces in the secondary system (Fardis 2009), that make the design cumbersome. In addition, requiring also a verification of the flexural resistance of the slab $\left(m_{R d} \geq m_{E d}\right.$, lowercase symbols referring to moments per unit width of the slab) is not consistent with the fact that high moments resulting from the imposed deformation assuming elastic behaviour are not realistic due to the additional deformation capacity of the slab in bending related to yielding of the reinforcement.

In case the imposed rotation $\psi_{s l a b, E}$ exceeds the capacity $\psi_{s l a b, R}$, unless shear reinforcement is provided, punching occurs (point (C) in Fig. 1a). In this case, the shear resistance diminishes rapidly and a further equilibrium state can be reached only if sufficient integrity reinforcement in form of bottom reinforcement passing through the column can be activated (Fig. 1c). As shown by several works (see for instance Fernández Ruiz et al. 2013; Habibi et al. 2014), the integrity reinforcement is an efficient method to allow for an alternative load carrying system after a local punching and to prevent progressive collapse. EC2:2004 (CEN 2004b) for instance, requires the placement of reinforcement bars in the compression zone crossing the column area to carry gravity loads after punching and to prevent progressive collapse. This reinforcement can be designed for an accidental design situation according to the simple method of EC2:2004 (CEN 2004b) or with the advanced approach of MC2010 (fib 2013). In the presence of integrity reinforcement, the behaviour after punching is characterised by a very limited stiffness against unbalanced moments, so that the imposed rotation $\psi_{\text {slab }}$ will have a limited influence on the residual strength (curve (e) in Fig. 1a). Although allowing to avoid a total collapse, provided that the $2^{\text {nd }}$ order effects can be carried by the primary system or by the still resting slab-column connections, this situation can be considered as a near collapse limit state of the floor and would be hardly reparable. For this reason, it should be prevented as a design situation so that the slab-column connection should be designed to avoid punching by ensuring adequate deformation capacity (point (C) in Fig. 1a).

\subsection{Prediction of deformation capacity}

The design for punching shear in EC2:2004 (CEN 2004b) under static actions requires the calculation of internal forces (total shear force, $V_{E d}$, and moment transferred from the column to the slab, $M_{E d}$ ) allowing determining the shear stress acting on the control perimeter, i.e., they are force-based. On the other hand, the provisions of EC8:2004 for secondary members require deformation-based checks, for which no guidance is provided in current provisions for flat slabs.

In contrast, North American codes (ACI 318-19 (2019) and CSA A23.3-14 (2014)) provide deformation-based criteria for the design of flat slab-column connections under horizontal actions. Both documents acknowledge that, based on experimental observations on slab-column connections under lateral loading, the ultimate slab rotation capacity 


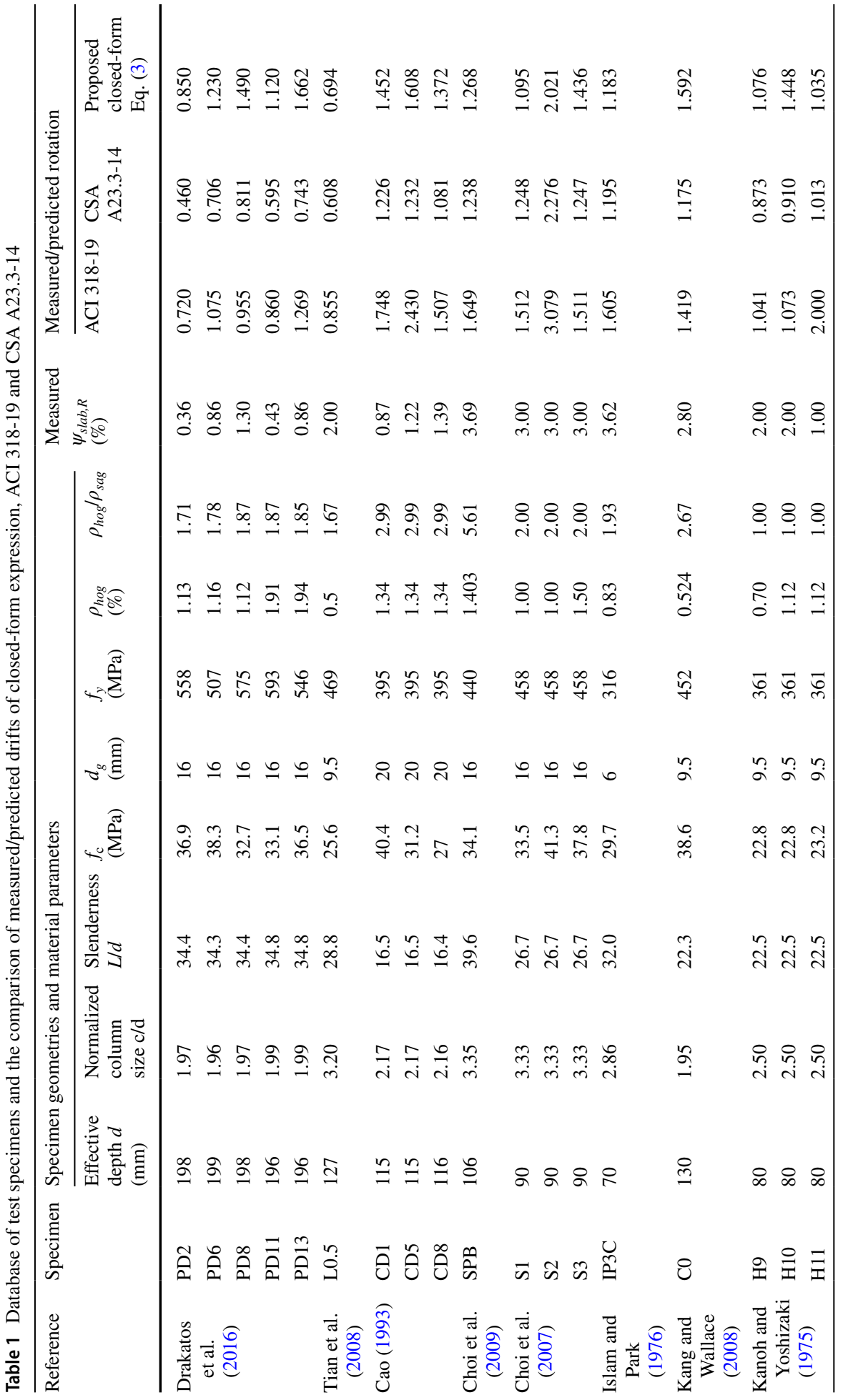




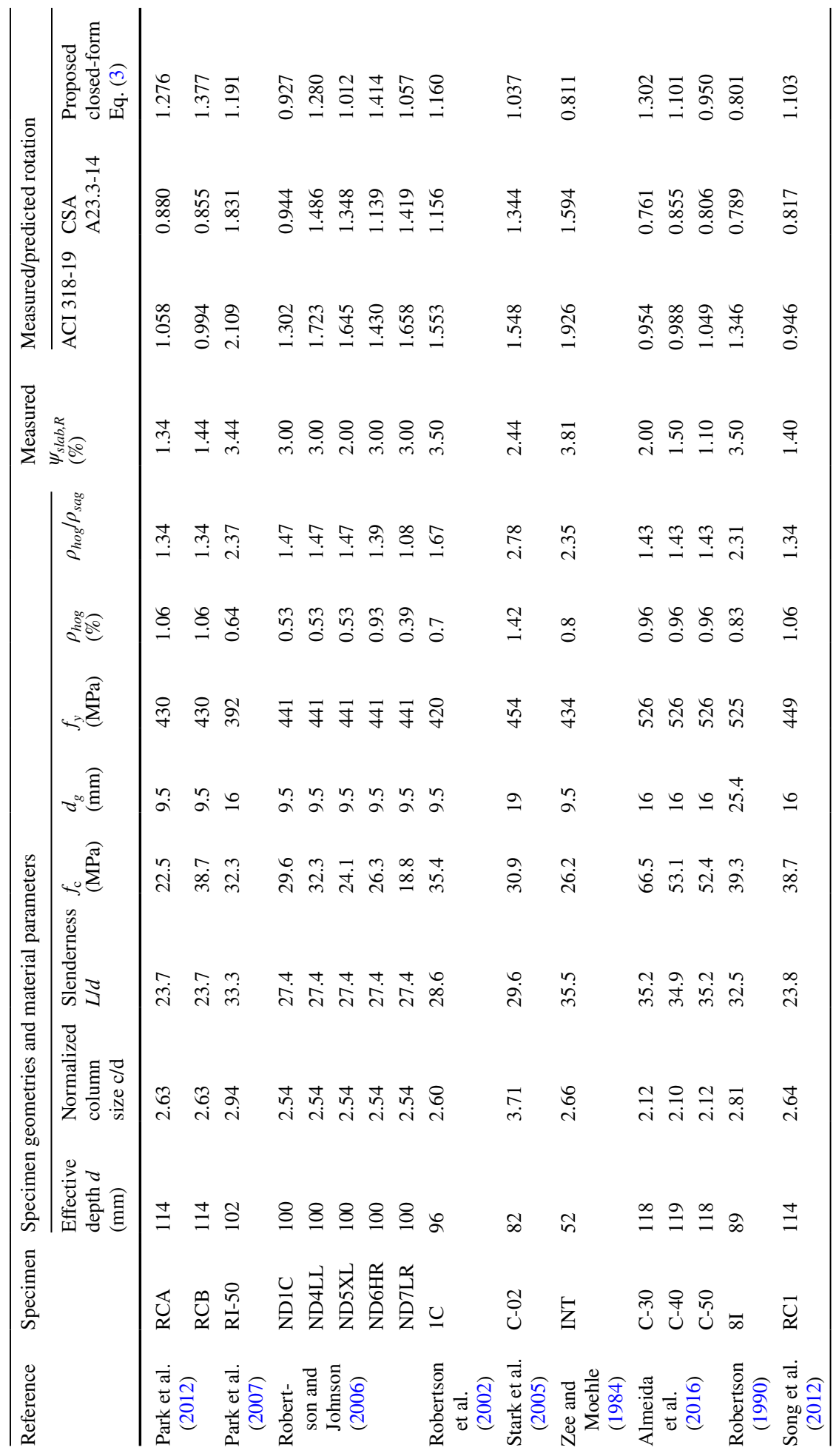




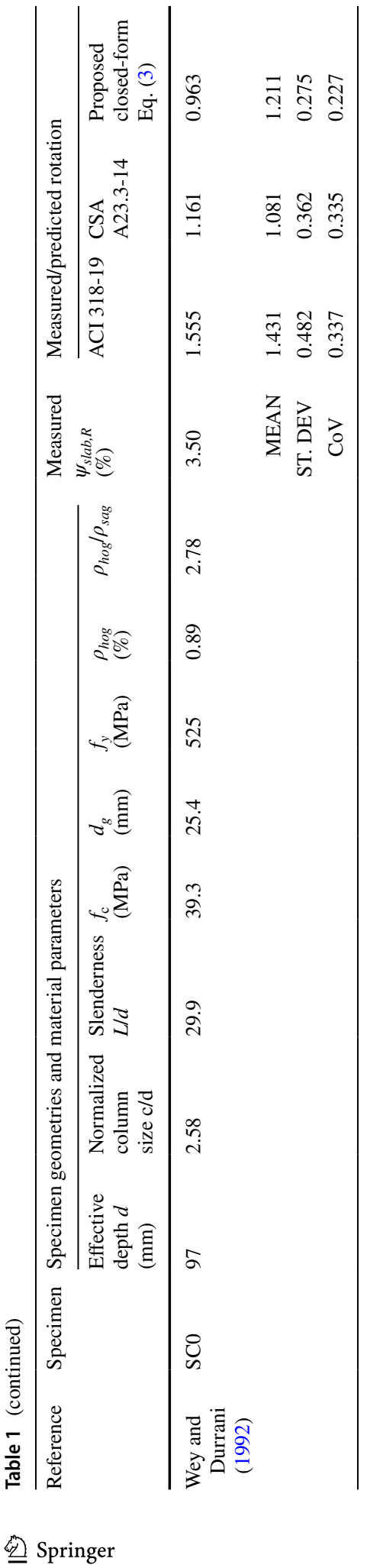


$\psi_{\text {slab,R }}$ depends on the Gravity Shear Ratio (defined as the ratio between the acting vertical shear force $V_{E d}$ and the centric punching shear resistance without shear reinforcement $V_{R d, c}$ where both eccentricity and imposed deformations are not considered) (Moehle 1996; Megally and Ghali 2000; Dilger et al. 2005; Hueste et al. 2007). In fact, the criteria of the North American codes can be seen as an explicit formulation of the relationship between punching shear resistance and rotation capacity discussed above (see curves (c) and (d) in Fig. 1a).

In this section, both similarities and discrepancies between the predictions of empirical formulae according to ACI 318-19 (2019) and CSA A23.3-14 (2014) and mechanicallybased models to predict the deformation capacity are discussed. For this purpose, a comparison against test results is required and hence a database of specimens was collected. The database used here adopts the work of Setiawan et al. (2019) comprising 50 specimens of internal slab-column connections without shear reinforcement and square columns subjected to unilateral reversed-cyclic loading. An additional filtering process was performed and following specimens were removed from the original collection:

- 3 outlier specimens denoted by Setiawan et al. (2019): AP1 and AP3 of Pan and Moehle (1989) and Control of Cho (2009);

- 10 specimens with high strength and lightweight concrete slab series of Emam et al. (1997) and Marzouk et al. (2001);

- 2 specimens with very low GSR ratio (<0.15): S4 and S5 of Morrison et al. (1983).

The final database (refer to Table 1) consists of 35 specimens with GSR (ACI 318-19) ranging from 0.18 to 0.85 , effective depth $(d)$ from 52 to $199 \mathrm{~mm}$, column size to slab depth ratio $(c / d)$ from 2 to 3.7 ; slab slenderness $(L / d)$ from 16 to 40 ; and hogging reinforcement ratio $\left(\rho_{\text {hog }}\right)$ from 0.39 to $1.94 \%$.

As depicted in Fig. 2a and b, the failure criteria for slabs without shear reinforcement define two regions: one where shear reinforcement is required (above the limit) and another where shear reinforcement is not required (below the limit). As shown in this figure, both criteria according to ACI 318-19 (2019) and CSA A23.3-14 (2014) can be seen as safe estimate of the drift ratio capacity according to tests in the collected database. Although they seem to follow the pattern reasonably well, the oversimplicity of the design expressions (only considering GSR as a single determining factor) is shown later to produce considerable scatter when dealing with individual specimens.

The design of secondary flat slab-column connections assuming the drift ratio as an imposed deformation is straightforward: the deformation capacity of the connections is checked based on the value of $G S R=V_{E d} / V_{R d, c}$ (using appropriate partial safety factors) and compared to the drift ratio demand $\psi_{\mathrm{E}}$ imposed by the primary seismic load resisting system. As discussed above, if the deformation capacity $\psi_{s l a b, R}$ is lower than the demand $\psi_{\text {slab,E}}$, punching shear reinforcement should be provided, or, alternatively, the GSR can be decreased, for example by increasing the column size or the concrete grade.

Ramos et al (2017) showed that empirical relationships similar to those of the North American codes can be adopted also when the GSR is calculated on the basis of EC2:2004 (CEN 2004b) or Model Code 2010 (fib 2013).

Mechanical models allowing to predict the rotation capacity of flat slabs $\psi_{\text {slab }, R}$ as function of all main parameters have been proposed recently by Drakatos et al. (2018), Setiawan et al. (2019) and by Broms (2020) for internal columns. The models by Drakatos et al. and by Setiawan et al. are based on the Critical Shear Crack Theory CSCT (Muttoni 2008) which means that they are fully consistent with the MC2010 (fib 2013) 
(a)

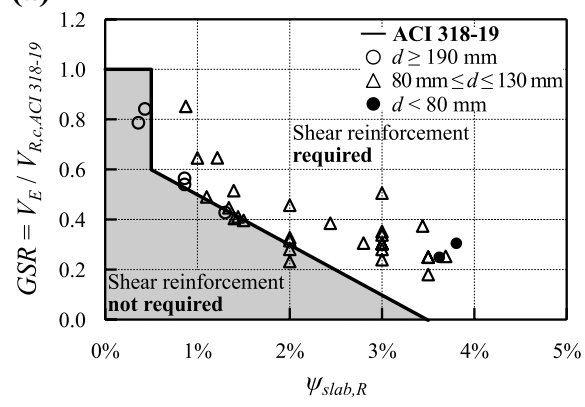

(c)

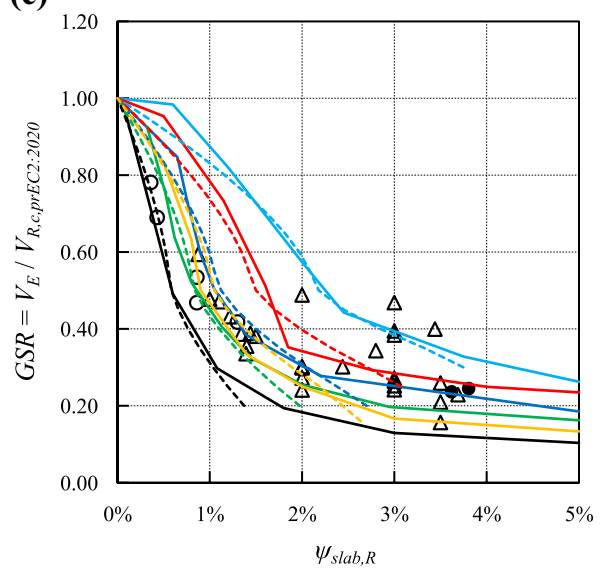

(b)
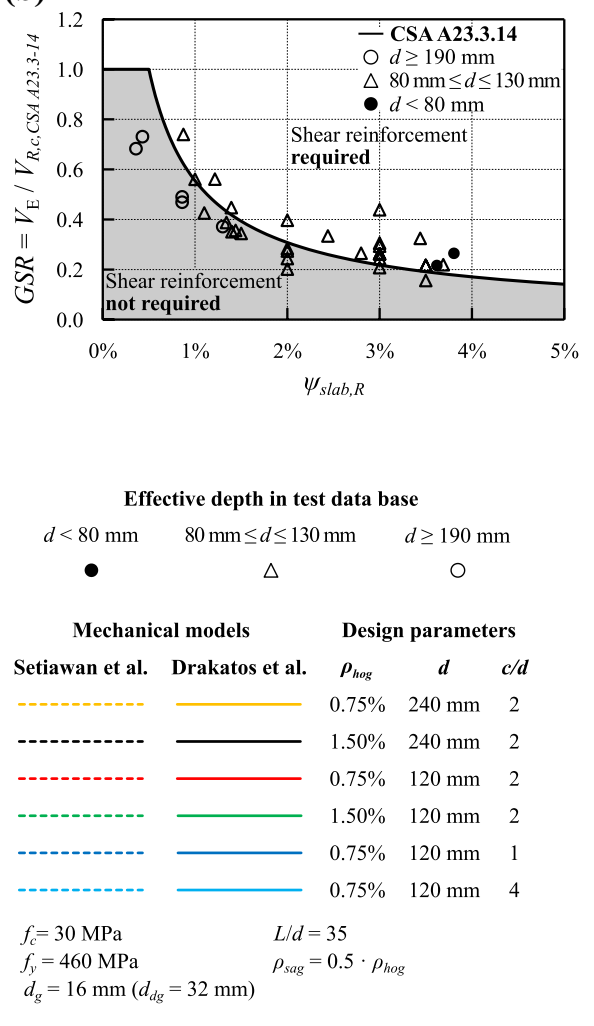

Fig. 2 Rotation capacity $\psi_{s l a b, R}$ as function of the Gravity Shear Ratio $V_{E} / V_{R, c}$ (all values unfactored) according to: a ACI 318-19; b CSA A23.3-14 and $\mathbf{c}$ the mechanical models by Drakatos et al. (2018) (continuous lines) and by Setiawan et al. (2019) (dashed lines); dots refer to tests from the collected database Table 1

formulation. As it can be observed in Fig. 2c, where the two models based on the CSCT are compared with the test results from database of tests (Table 1), the drift capacity depends mostly on the GSR (confirming the studies described above), but other parameters also play a significant role. As it will be shown later, the most important parameters are the effective depth $d$ (size effect, with decreasing deformation capacity $\psi_{\text {slab }, R}$ for deeper slabs), the column size (with increasing $\psi_{s l a b, R}$ for larger columns) and the hogging reinforcement ratio $\psi_{h o g}$ (with $\psi_{\text {slab }, R}$ decreasing for larger reinforcement ratios). In addition, the slab slenderness $L / d$ also plays a significant role (with increasing $\psi_{\text {slab }, R}$ for slender slabs). The fact that the slab thickness influences not only the punching shear resistance (size effect), but also the deformation capacity, has already been demonstrated by Muttoni (2008) for the case of concentric punching and has been recently confirmed for the case of imposed lateral deformations by three mechanical models described above. These are important findings since the empirical criteria currently defined in North American codes (see Fig. 2a, b) were fitted on tests on specimens of slab-column connections which are usually relatively thin $(<130 \mathrm{~mm}$, excluding Drakatos et al. (2016) series conducted with relatively high GSRs) and with medium-large 
(a)

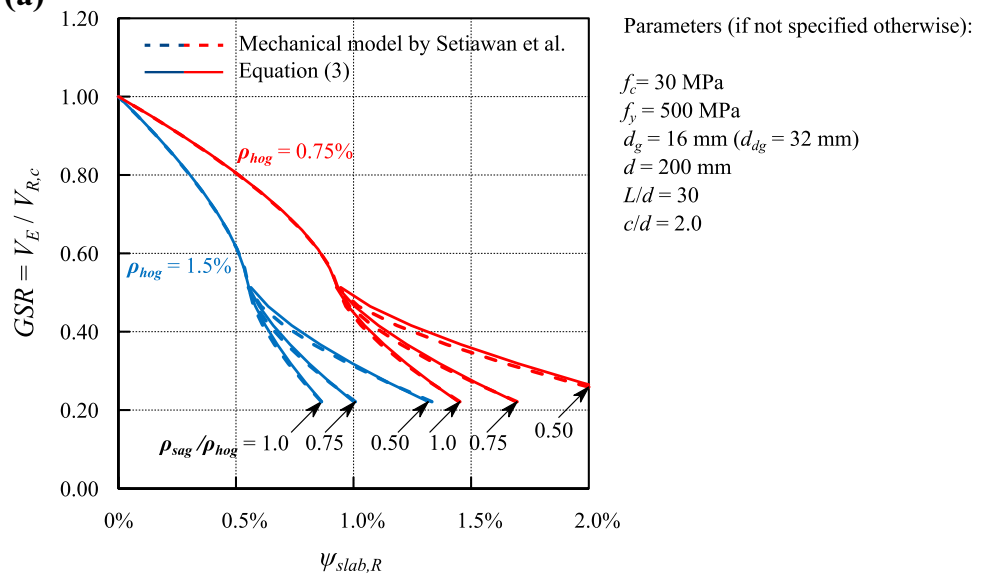

(b)

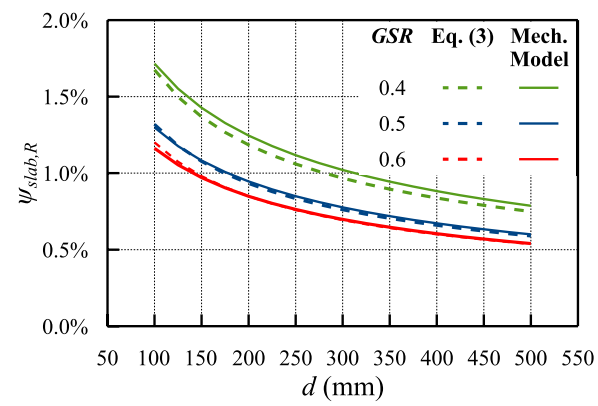

(d)

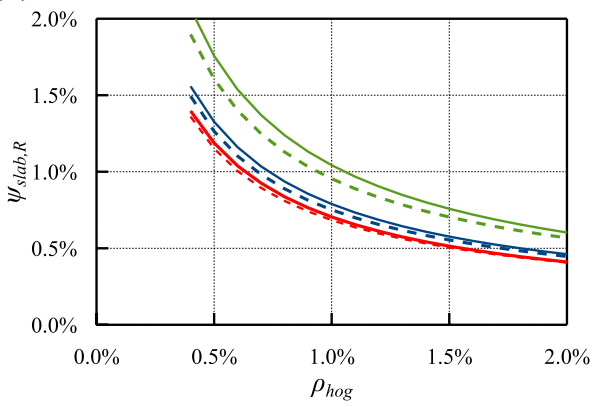

(c)

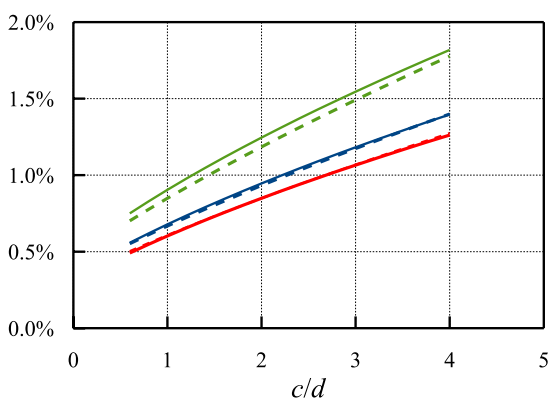

(e)

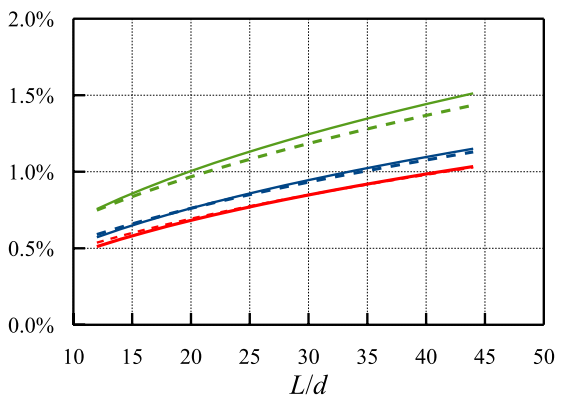

Fig. 3 Rotation capacity $\psi_{\text {slab,R }}$ according to the mechanical model by Setiawan et al. (2019) and Eq. (3) as function of: a the Gravity Shear Ratio $V_{E} / V_{R, c}$ and the sagging reinforcement ratio $\psi_{\text {sag }}$ in the column region; b the effective depth $d$; $\mathbf{c}$ the size $c$ of a square column; $\mathbf{d}$ the hogging reinforcement ratio $\psi_{\text {hog }}$ and $\mathbf{e}$ the slenderness ratio $L / d$

size columns ( $c / d$ between 2 and 5). Only a few tests are available with an effective depth corresponding to typical practical European cases, and most of them have been conducted with relatively high GSRs.

Interestingly, the parameters influencing the rotation capacity $\psi_{\text {slab,R }}$ intervene in a similar manner also in the calculation of the punching shear resistance $V_{R, c}$ of slabs 

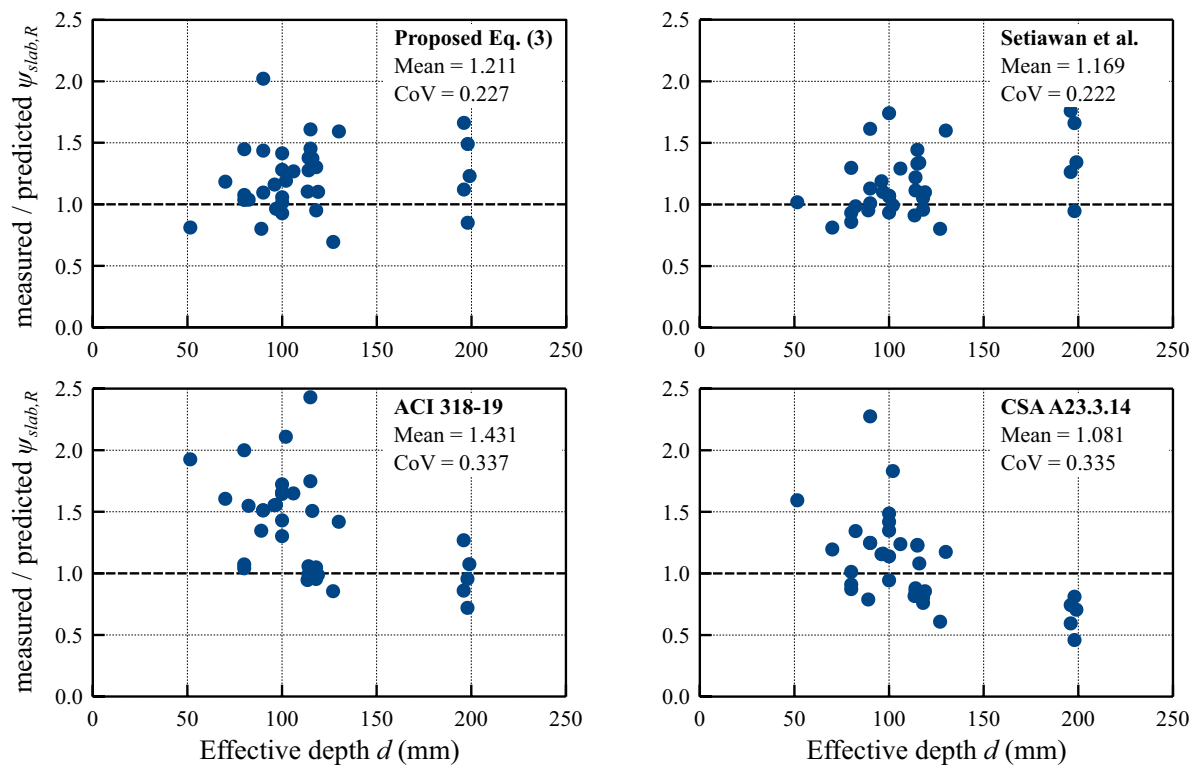

Fig. 4 Measured vs predicted rotation capacities $\left(\psi_{\text {slab,R }}\right)$ of all specimens reported in Table 1

without shear reinforcement. According to the closed-form formulation derived analytically from the CSCT (Muttoni et al. 2018) and its design value adopted in the draft for the $2^{\text {nd }}$ generation of EC2 (called in the following prEC2:2020 (SC2/WG1/CDG 2020)), the punching shear resistance for internal columns supporting slabs without shear reinforcement can be expressed as:

$$
V_{R d, c}=\frac{3.8}{\gamma_{V}} b_{0,5}^{1 / 2} \cdot d^{3 / 2}\left(100 \rho_{h o g} f_{c k} \frac{d_{d g}}{d \sqrt{L /(36 \cdot d)}}\right)^{1 / 3}
$$

where $\gamma_{V}$ is the partial safety factor for shear and punching (proposed as 1.40), $d$ is the effective depth of the slab, $b_{0,5}$ is the length of control perimeter located at a distance of $0.5 \cdot d$ from the face of the column, $\rho_{\text {hog }}$ is the hogging reinforcement ratio, $f_{c k}$ is the concrete compressive strength in $\mathrm{MPa}, d_{d g}$ is a dimension which describes the roughness of the critical shear crack and can be assumed as function of the aggregate size $d_{g}$ by $d_{d g}=d_{g}+16 \mathrm{~mm}$ for concrete strengths $f_{c} \leq 60 \mathrm{MPa}$ and $L$ is the slab span.

As shown in Fig. 3b-e, based on a detailed comparison with the mechanical models by Drakatos et al. (2018) and by Setiawan et al. (2019), the rotation capacity $\psi_{s l a b, R}$ can be assumed to be approximatively proportional to $d^{-1 / 2}$ (size effect), to $\left(b_{0,5} / d\right)^{3 / 4}$, to $\rho_{h o g}{ }^{-3 / 4}$ and to $(L / d)^{1 / 2}$.

With respect to the influence of the GSR, as depicted in Fig. 3a, the following three regimes delimitated by changes in the slopes can be observed: (i) for high GSRs (between $\sim 0.5$ and 1.0), the behaviour is dominated by the hogging moments; (ii) for average GSRs (between $\sim 0.2$ and $\sim 0.5$ ), the moments transferred from the columns to the slab become so significant, that the slab moments become positive near to the column (and since the sagging reinforcement ratio is typically smaller, the rotation capacity increases 
rapidly); (iii) for very low GSRs, the sagging reinforcement near to the column can yield (potentially increasing again the rotation capacity). As stated by Setiawan et al. (2019) and by Broms (2020), the mechanism related to yielding of the sagging reinforcement in the column region is affected by too many uncertainties and should not be considered for design (in addition, it occurs for very low GSRs which are less significant for practical cases). The influence of the elastic deformation under sagging moments is shown in Fig. 2c (model by Setiawan et al. (2019), yielding of sagging reinforcement not considered). As shown in this figure, the influence of GSR on the rotation capacity $\psi_{s l a b, R}$ should be considered accounting also for the deformation of sagging reinforcement. Based on these considerations, the rotation capacity $\psi_{\text {slab,R }}$ of internal columns can be expressed analytically as follows:

$$
\psi_{\text {slab }, R}=0.60 \% \cdot\left(\frac{b_{0,5}}{10 \cdot d} \cdot \frac{1}{100 \cdot \rho_{\text {hog }}}\right)^{3 / 4} \cdot\left(\frac{10 \cdot d_{d g}}{d} \cdot \frac{L}{36 \cdot d}\right)^{1 / 2} \cdot f(G S R)
$$

where coefficient $0.60 \%$ results from the calibration on the basis of the mechanical models and the function $f(G S R)$ is:

$$
\begin{gathered}
f(G S R)=1-(2 \cdot G S R-1)^{3 / 2} \text { for } 0.50 \leq G S R \leq 1.00 \\
f(G S R)=1+1.2 \cdot(1-2 \cdot G S R)^{3 / 2} \cdot\left(\frac{\rho_{\text {hog }}}{\rho_{\text {sag }}}\right)^{4 / 3} \leq 2 \text { for } 0.20 \leq G S R<0.50
\end{gathered}
$$

where the Gravity Shear Ratio GSR is equivalent to the ratio $V_{E d} / V_{R d, c}, \rho_{s a g}$ is the sagging reinforcement ratio and the ratio $\rho_{\text {hog }} / \rho_{\text {sag }}$ should not be considered larger than 2.0 , which is consistent to the proposal of Setiawan et al. (2019). In addition, the value of $f(G S R)$ for GSR between 0.2 and 0.5 (Eq. 3c) shall not be taken larger than 2 to prevent overly high drift predictions for slabs with a combination of low GSR and high $\rho_{\text {hog }} / \rho_{\text {sag }}$. Since Eq. (2) has been derived analytically from the MC2010 equations (Muttoni et al. 2018), the gravity shear ratio GSR considered in Eq. (3) can be calculated using $\tau_{R d, c}$, according to either MC2010 or to prEC2:2020. In the assessment of test database presented here, the GSR for the closed-form expression (Eq. 3) is always calculated based on prEC2:2020, unless stated otherwise.

Figure 4 shows the ratio measured vs predicted rotation capacities calculated using the mechanically-based models (Setiawan et al. (2019) and the closed-form expression of Eq. (3)) and the empirically-based formulae (ACI 318-19 \& CSA A23.3-14) of all 35 specimens reported in Table 1 as a function of the effective depth. The mean value and coefficient of variation $(\mathrm{CoV})$ of each model is also given in the same graph. Observing the pattern in Figs. 4a, b, it can be seen that the predictions of the closed-form expression are in excellent agreement with Setiawan et al. which further confirms the previous observation shown in Fig. 3. By comparing Figs. 4a-d, it can be seen that the scatter of the empiricallybased formulae is more significant $(\mathrm{CoV} \approx 0.3)$ than the mechanically-based one ( $\mathrm{CoV}$ $\approx 0.2$ ). This is mainly due to the fact that the empirically-based formulae do not account for significant factors as for instance the size effect as shown in this figure (decreasing trend of measured/predicted deformation capacity for increasing effective depth). Amongst all, the ACI 318-19 predictions are the most conservative and this is consistent with Fig. 2a where the line separating the two regions provides a lower-bound estimate of the test results. It has to be noted that the relatively large scatter of all approaches can also be attributed to the differences in the test setups (Drakatos et al. 2016) and in the cyclic loading protocols 
(increased damage for loading histories with more repetitive cycles), to the fact that several tests have been conducted on very thin slabs, that in some tests, the reported deformation capacity also includes the column deformation $\left(\psi_{i s d, R}\right.$ instead of $\left.\psi_{\text {slab,R }}\right)$ and to potentially different definitions of failure (\% of moment loss or loss of the capability to carry gravity loads).

In addition, these comparisons refer to internal columns, whereas edge and corner columns have rarely been investigated. For these reasons, one can conclude that for the validation of the proposed expression, there is a clear need for new tests on slabs with a reasonable thickness not only on internal, but also on edge and corner slab-column connections.

\subsection{Typical gravity shear ratios in buildings}

In a practical design for persistent design situations according to EC2:2004, the design value of the shear force $V_{E d \text {,persistent }}$ in the slab around the column is calculated on the basis of the self-weight and additional permanent loads multiplied with the partial safety factor $\gamma_{G}$ and the characteristic value of the imposed gravity load multiplied with the partial safety factor $\gamma_{Q}$ (according to EC0:2002 (CEN 2002a), the recommended values are $\gamma_{G}=1.35$ and $\left.\gamma_{Q}=1.50\right)$. In addition, to account for unsymmetrical loading and geometrical conditions, as well as for neglected imposed deformations resulting from shrinkage and temperature variations in the building, the design value of the shear force shall be increased by a factor $\beta_{e}$. According to EC2:2004, without a detailed analysis, for slabs considered as secondary systems (i.e. where the horizontal actions are carried predominantly by a bracing system), following values may be assumed for $\beta_{e}: 1.15$ for internal columns, 1.4 for edge columns and 1.5 for corner columns. It has to be noted that this approach is equivalent to a reduction of the punching shear resistance due to unsymmetrical conditions and imposed deformations: see point (B) in Fig. 1a.

With respect to the design shear force in the slab $V_{E d, \text { seismic }}$ for seismic design situations according to EC8:2004, the self-weight and the additional permanent loads may be

Fig. 5 Ratio $V_{E d, \text { sesmic }} / V_{E d, p e r s i s t e n t}$ (approximatively equivalent to the upper limit of the GSR) for typical flat slabs expressed as a function of the ratio imposed vertical loads $q_{k}$ /permanent loads $g_{k}$ (buildings designed according to EC2:2004, EC0:2002 and EC1:2002)

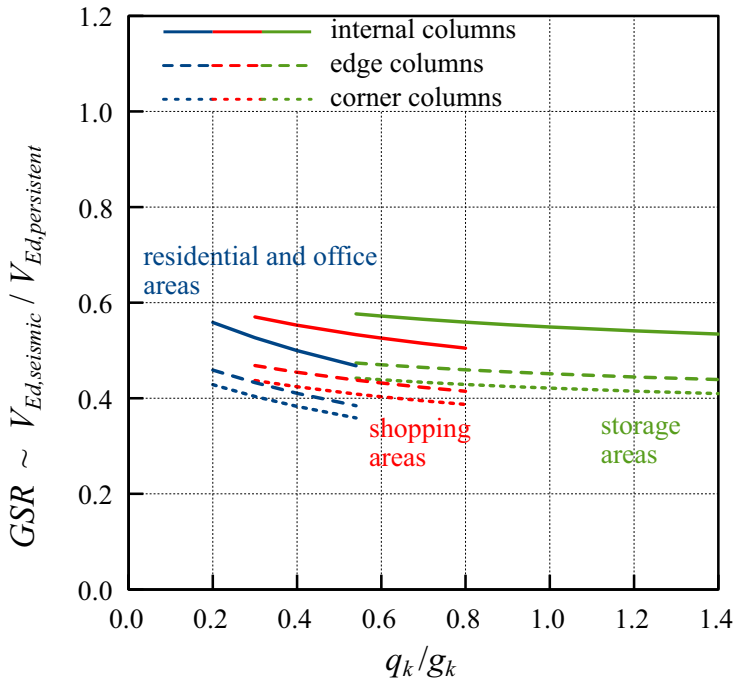




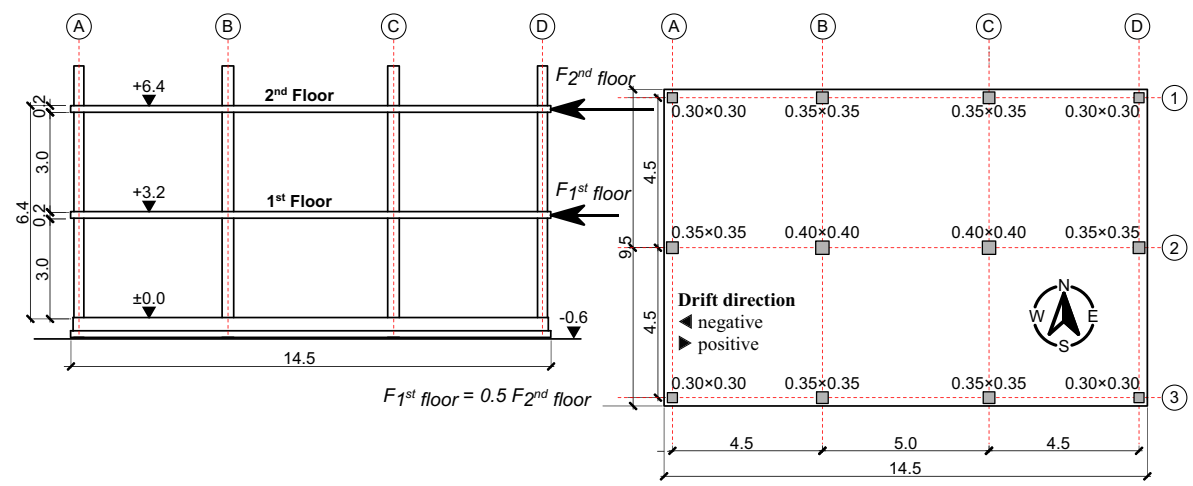

Fig. 6 Side and in-plan view of the two-stories flat-slab frame (dimensions in $\mathrm{m}$ )

considered with their nominal values and the imposed vertical load may be reduced by coefficient $\psi_{2}$ (varying between 0.3 and 0.8 depending on the type of loading according to EC0:2002). Since the effect of the imposed deformations (interstorey drift) is considered explicitly with the verification of the rotation capacity, and assuming approximately the same contributory areas of the vertical actions for persistent and seismic design situations, the ratio of the shear forces between both situations is approximately:

$$
\frac{V_{\text {Ed,seismic }}}{V_{\text {Ed,persistent }}} \approx \frac{g_{k}+\psi_{2} \cdot q_{k}}{\beta_{e} \cdot\left(\gamma_{G} \cdot g_{k}+\gamma_{Q} \cdot q_{k}\right)}
$$

Since the Gravity Shear Ratio compares the acting shear force with the punching shear resistance, the design value of the latter should also be accounted for. For persistent design situations, the characteristic value of the punching shear resistance $V_{R k, c}$ is reduced by a partial safety factor accounting for the uncertainties related to the material strength, the geometry and the resistance model. According to EC2:2004, this value is $\gamma_{C}=1.50$ for persistent design situations and $\gamma_{C}=1.20$ for accidental design situations (the latter accounting for a reduced reliability index; similar values are considered in the latest draft prEC2:2020, namely $\gamma_{V}=1.40$ and 1.15 ). With respect to the partial safety factor for the resistance under seismic design situations, despite the fact that from a point of view of reliability considerations, this design situation is theoretically an accidental situation, according to EC8:2004, the same partial factors as according to EC2:2004 for the persistent design situation are recommended. According to the comment in EC8:2004, this choice is justified by the fact that under seismic actions, the resistance is reduced by the effect of cyclic actions. In fact, in the approach proposed in this paper, this effect is already accounted for in the proposed failure criterion (see Fig. 2, where the mechanical model as well as the tests considered in development of the empirical relationships according to ACI 318-19 (2019) and standard CSA A23.3-14 (2014) consider cyclic actions). Nevertheless, considering the increased uncertainties related to the calculation of the shear force $V_{E d}$ for a seismic design situation, the imposed deformation $\psi_{s l a b, E}$ in the seismic design situation and its deformation capacity $\psi_{\text {slab,R }}$, in absence of a complete reliability study, the choice of considering the same partial safety factor $\gamma_{C}$ (or $\gamma_{V}$ ) as for the persistent design situation seems to be justified. Following this assumption, and assuming that the slab-column connection is designed for the persistent design situation without overstrength, the upper limit of the GSR at seismic design 


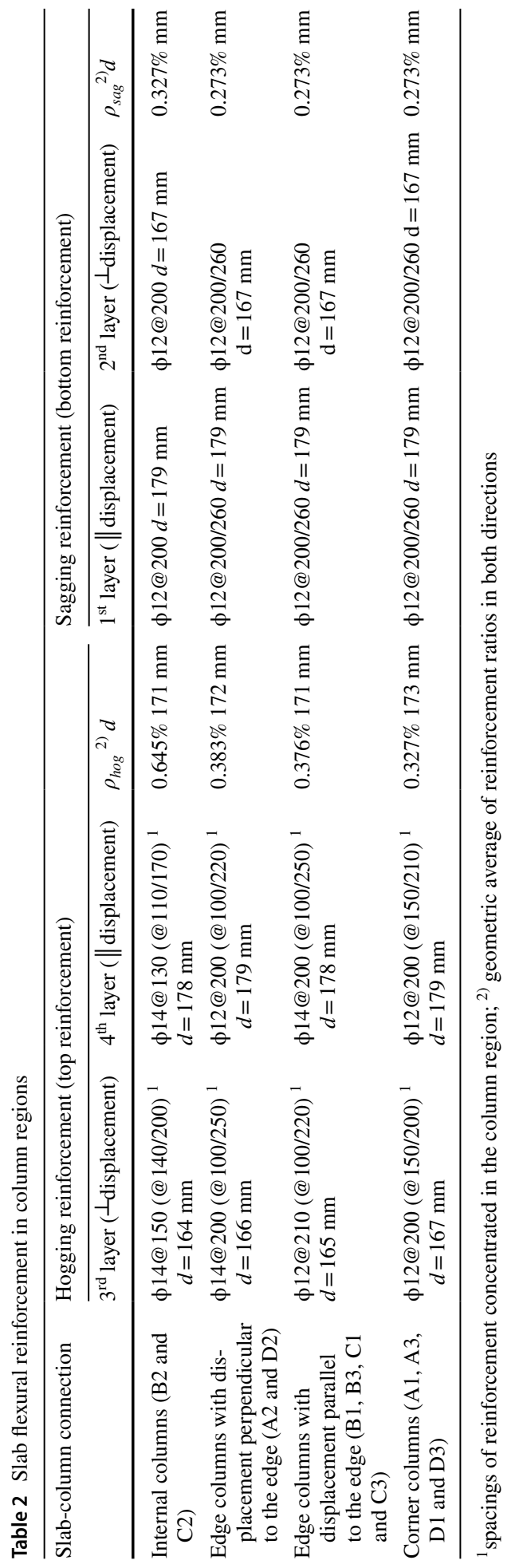


situation corresponds to the ratio of the design values of the shear force as expressed by Eq. (4).

As shown in Fig. 5 where this ratio for typical flat slabs of buildings designed according to EC2:2004 (CEN 2004b), EC0:2002 (CEN 2002a) and with the actions according to $\mathrm{EC1:2002} \mathrm{(CEN} \mathrm{2002b)} \mathrm{is} \mathrm{expressed} \mathrm{as} \mathrm{a} \mathrm{function} \mathrm{of} \mathrm{the} \mathrm{ratio} q_{k} / g_{k}$, typical values of the upper limit of the $G S R$ are in the ranges $0.47 \div 0.58$ for internal columns, $0.38 \div 0.48$ for edge columns and $0.36 \div 0.44$ for corner columns. In a practical case, lower values can be required to fulfil the requirement $\psi_{i s d, E} \leq \psi_{i s d, R}$ for the seismic design situation.

\section{Experimental programme}

The SlabSTRESS research programme was conceived to simultaneously study the global and local response of flat-slab frames under both gravity and seismic actions. The experimental programme involved full-scale testing on a two-storey building at the ELSA Reaction-Wall facility of the European Commission's Joint Research Centre in Ispra, Italy. The SlabSTRESS project was part of the transnational access activities of the SERA project (www.sera-eu.org).

\subsection{Test specimen}

The reinforced concrete structure to be tested was designed as a simple building with shear walls (primary seismic structure) and a flat-slab frame (secondary seismic structure) which consists of two flat slab floors supported on columns (see Fig. 6 for the tested structure).

The floors are ordinary reinforced concrete flat slabs with thickness $200 \mathrm{~mm}$. The spans are $4.5 \mathrm{~m}$ and $5 \mathrm{~m}$ in the longitudinal direction (direction of the imposed displacements) and $4.5 \mathrm{~m}$ in the transverse direction. The storey height is $h=3.2 \mathrm{~m}$. Columns cross-sections are square with dimensions $0.4 \mathrm{~m}, 0.35 \mathrm{~m}$ and $0.3 \mathrm{~m}$ for internal, edge and corner columns, respectively. These were chosen in order to obtain a stiffness ratio of the internal, lateral and corner columns close to 2, following a common design choice (Fardis 2009).

The preliminary choice was to design the flat slabs with a gravity shear ratio close to 0.4 (factored value, lower values if $\gamma_{C}$ is not considered, see Fig. 12). This choice had several motivations. As shown in Sect. 3, this GSR fits in the values corresponding to common design situations. In addition, the aim was to provide more realistic size slab results since most existing tests in the literature have a limited depth for this level of GSR (see Fig. 2a). The existing results show that reinforcement yielding and higher ultimate rotations are obtained for GSR equal to or less than 0.4, a condition convenient for the seismic response and requiring a verification in a real size test.

The slabs of the two floors were designed for the ULS gravity load combination (persistent design situation) governing the design effects. The flexural reinforcement design and punching resistance verifications were carried out on the basis of EC2:2004 (CEN 2004b). Two bottom bars in each direction were placed at each connection, following the provision of EC2:2004 to prevent progressive collapse (integrity reinforcement). The anchorage at the slab free edge was a L shaped bend, as commonly used in the practice in several European countries.

On the basis of the gravity loading design, and of the choice of the column size to slab thickness ratio, the slab-column connections at the first floor were not reinforced against punching shear. The second-floor slab was reinforced with headed studs as shear 
(a)

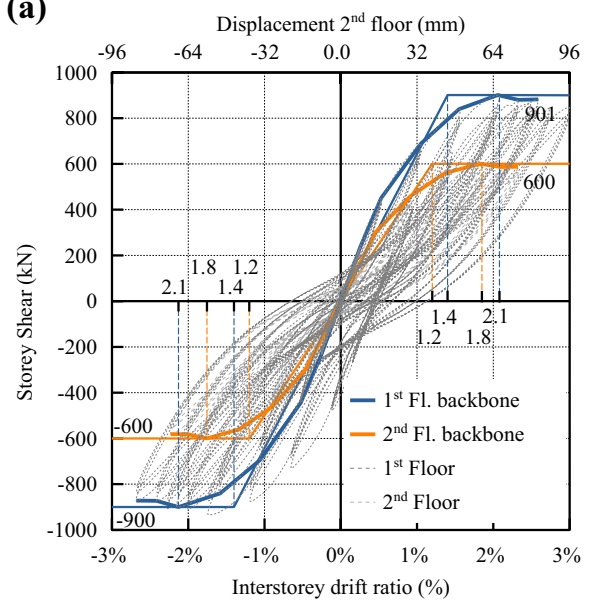

(b)

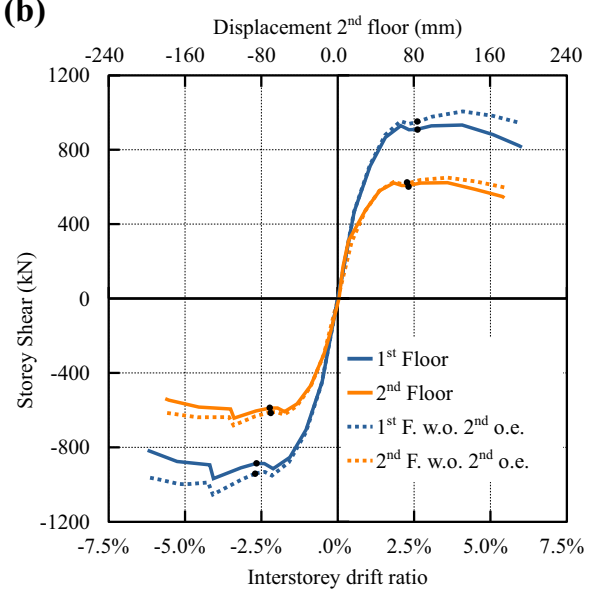

Fig. 7 Global behaviour of the flat slab frame for a test CYC-1 and b both tests with measured values (continuous curves) and with $2^{\text {nd }}$ order effects subtracted (dashed curves, "w.o. $2^{\text {nd }}$ o.e." in the legend, black dots indicate the limits between CYC-1 and CYC-2)

reinforcement. Though not required by the gravity load design, this choice was made to test the performance of slab-column connections of different configurations (internal, edge and corner and two flexural reinforcement layouts) when punching shear reinforcement is used in a flat slab with realistic thickness.

Using the same layout, the slab-column connections B2, C2 and C3 of the first floor were strengthened using post-installed bolts after an initial testing phase with significant interstorey drifts that produced damage on some of the slab-column connections. The purpose was to verify the effectiveness of post-installed bolts in earthquake-damaged connections of a complete full-scale structure with realistic dimensions. Table 2 describes the flexural reinforcement of all slab-column connections. Additional details as well as description of shear reinforcement can be found in Coronelli et al. (2021).

With respect to the columns, the reinforcement was designed on the basis of the maximum unbalanced moment that can be carried by the slab (flexural resistance of the slabcolumn connection) assuming mean material properties. The resulting longitudinal reinforcement ratios for internal, edge and corner columns were approximatively $1 \%, 1.5 \%$ and $2 \%$, respectively. This aimed to a "strong column-weak slab" condition, because the testing program (see also the following Sect. 4.3) included tests at drifts levels corresponding to slab failure around the column, and high moment transfer. In addition, to force the development of plastic hinges only at the column bases, the longitudinal reinforcement was doubled in all cross sections except the base region. To prevent brittle failures at the column base, closely-spaced stirrups (spacing to longitudinal bar diameter ratio equal to 5) were provided, to develop plastic rotation without premature buckling of the compression bars. 


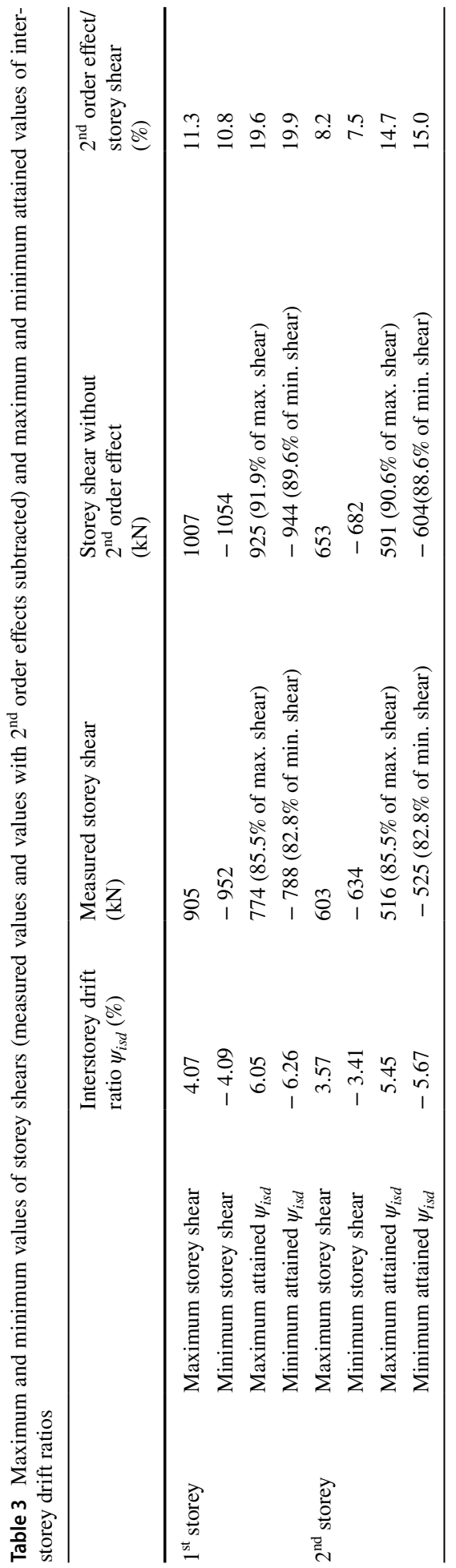




\subsection{Materials}

The flat slab structure, the columns and the foundations were designed with normalstrength concrete. For the reinforcing steel used in the floor slabs, foundations and column bases, S500 Class $\mathrm{C}$ reinforcement was chosen $\left(f_{y k}=500 \mathrm{MPa}\right)$ whereas for the columns, ductility Class B reinforcement was used. The concrete compressive strength measured on cylinders at the age of cyclic testing (about 330 days after casting) was $f_{c}=36.4 \mathrm{MPa}$. The mean steel yield strength and ultimate elongation of the reinforcing steel used in the floor slabs were $f_{y}=518 \mathrm{MPa}$ and $\varepsilon_{t}=12.3 \%$ for the bars $\phi 12 \mathrm{~mm}$ and $f_{y}=515 \mathrm{MPa}$ and $\varepsilon_{t}=10.3 \%$ for the bars $\phi 14 \mathrm{~mm}$.

\subsection{Testing programme}

The test programme included seismic tests and cyclic tests. The seismic tests consisted in a pseudo-dynamic investigation of the structure treated as part of a building with two substructured ductile shear walls which were simulated numerically. Details and results of the seismic tests are given in Coronelli et al. (2021).

In order to analyse the deformation capacity, after the seismic tests, quasi-static tests were performed with cyclic loading on the flat-slab frame. The aim of these tests was to study: (i) the redistribution within the storeys of the effects caused by lateral action; (ii) the response of different types of slab-column connections (corner, edge and interior) with realistic boundary conditions; (iii) the ultimate rotations and failure modes of the different connections; (iv) the effect of different layouts of longitudinal and shear reinforcement common in the European design practice and (v) the effectiveness of the integrity reinforcement to carry gravity loads after local failure.

A first test CYC-1 was carried out up to the first punching failure at about $2.5 \%$ drift ratio. A cyclic displacement was imposed on the second floor with average drift ratios (displacement of $2^{\text {nd }}$ floor $\left./\left(2 \cdot h_{s}\right)\right) \psi_{\text {isd,ave }}=0.25 \%, 0.5 \%, 1 \%, 1.5 \%, 2 \%, 2.25 \%$ and $2.5 \%$ with 3 cycles per drift level. A force half of the measured horizontal force at the second floor

Fig. 8 Ratios between interstorey drift ratios $\psi_{i s d}$, and average drift ratio $\psi_{\text {isd, ave }}$ (only peaks of all cycles represented); black dots indicate the limits between CYC-1 and CYC-2

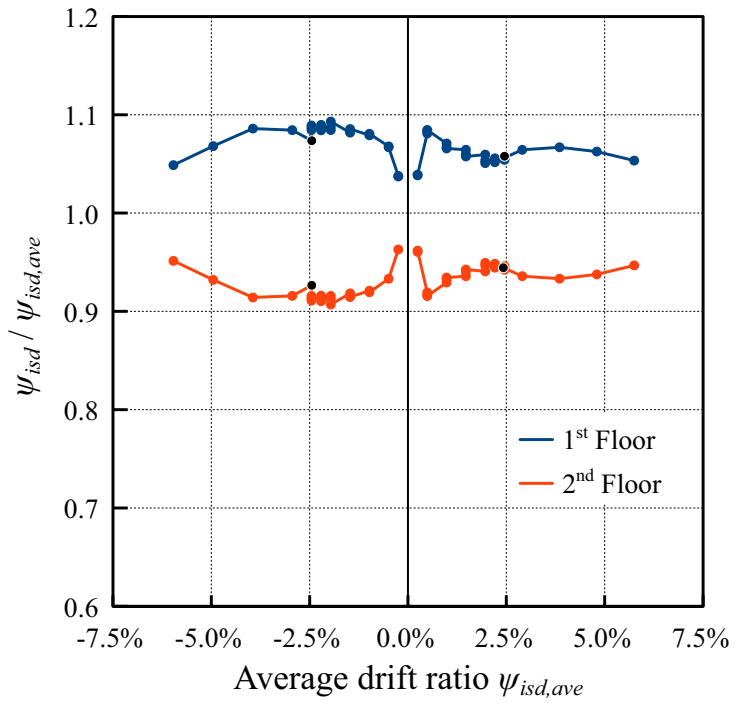




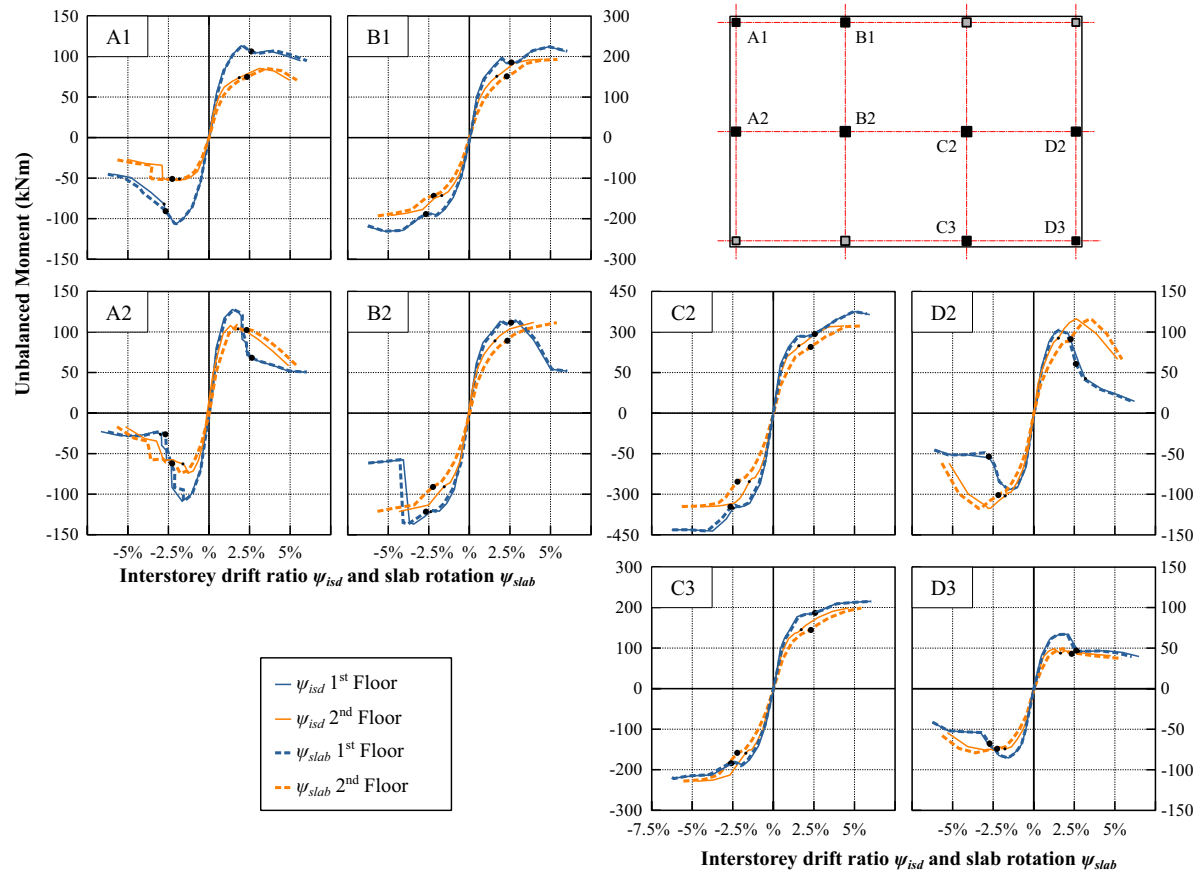

Fig. 9 Local behaviour of the slab-column connection (unbalanced moment as a function of the interstorey drift ratios $\psi_{i s d}$ and of the slab rotations $\psi_{\text {slab }}$ ) for the peak displacements of all cycles (black dots refer to the limit between CYC-1 and CYC-2)

was imposed on the first floor. After test CYC-1, some slab-to-column connections on the first floor were strengthened with post-installed bolts and the additional loads have been slightly modified to avoid the total collapse of the already failed connections, for details, see Coronelli et al. (2021). Then, a second cyclic test CYC-2 was carried out up to $6 \% \mathrm{drift}$ ratio $\left(\psi_{\text {isd,ave }}=2.5 \%, 3 \%, 4 \%, 5 \%\right.$ and $6 \%$ with a single cycle per drift level) to assess the ultimate rotations of the connections and the effectiveness of the retrofitting of damaged slab-column connections.

\section{Results of cyclic tests}

\subsection{Global behaviour}

Figure 7a shows the behaviour of the slabs-columns frame in terms of relationships between storey shear forces and the interstorey drift ratios for test CYC-1 (up to a drift ratio $\psi_{\text {isd,ave }}$ of $2.5 \%$ ). The hysteretic curves, the envelope curves and the idealized quadrilinear relationship are presented for both floors. One can observe that nominal yielding points, determined according to Annex B of EC8:2004 (CEN 2004a), are attained for $\psi_{\text {isd }}$ of $1.2 \%$ and $1.4 \%$ for the $1^{\text {st }}$ and the $2^{\text {nd }}$ floor, respectively. The maximum shear forces are attained for $\psi_{i s d}$ of $1.8 \%$ and $2.1 \%$. The envelopes are presented in Fig. $7 \mathrm{~b}$ for both tests (the limit between CYC-1 and CYC-2 is represented by black dots). Since the $2^{\text {nd }}$ 


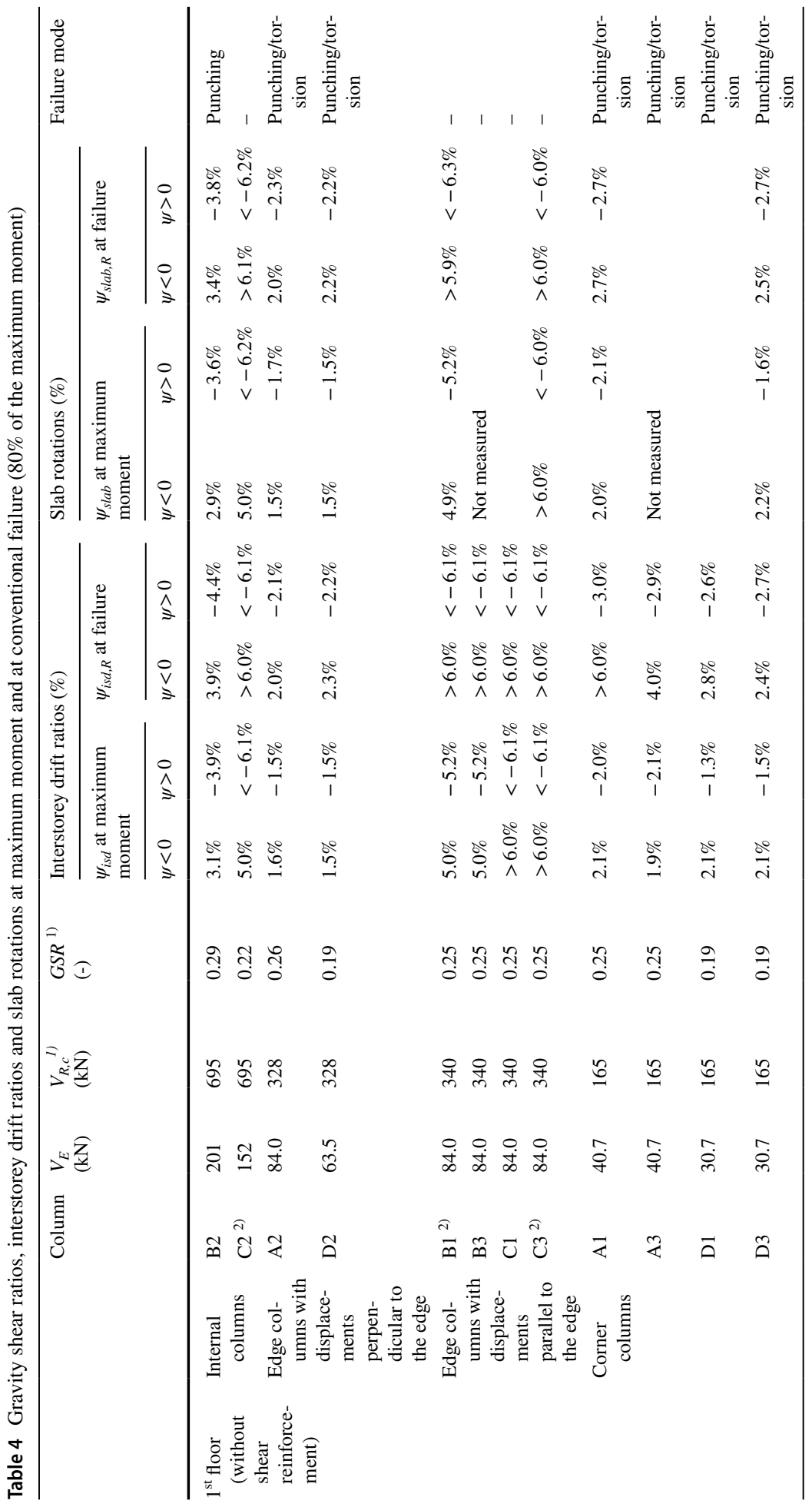




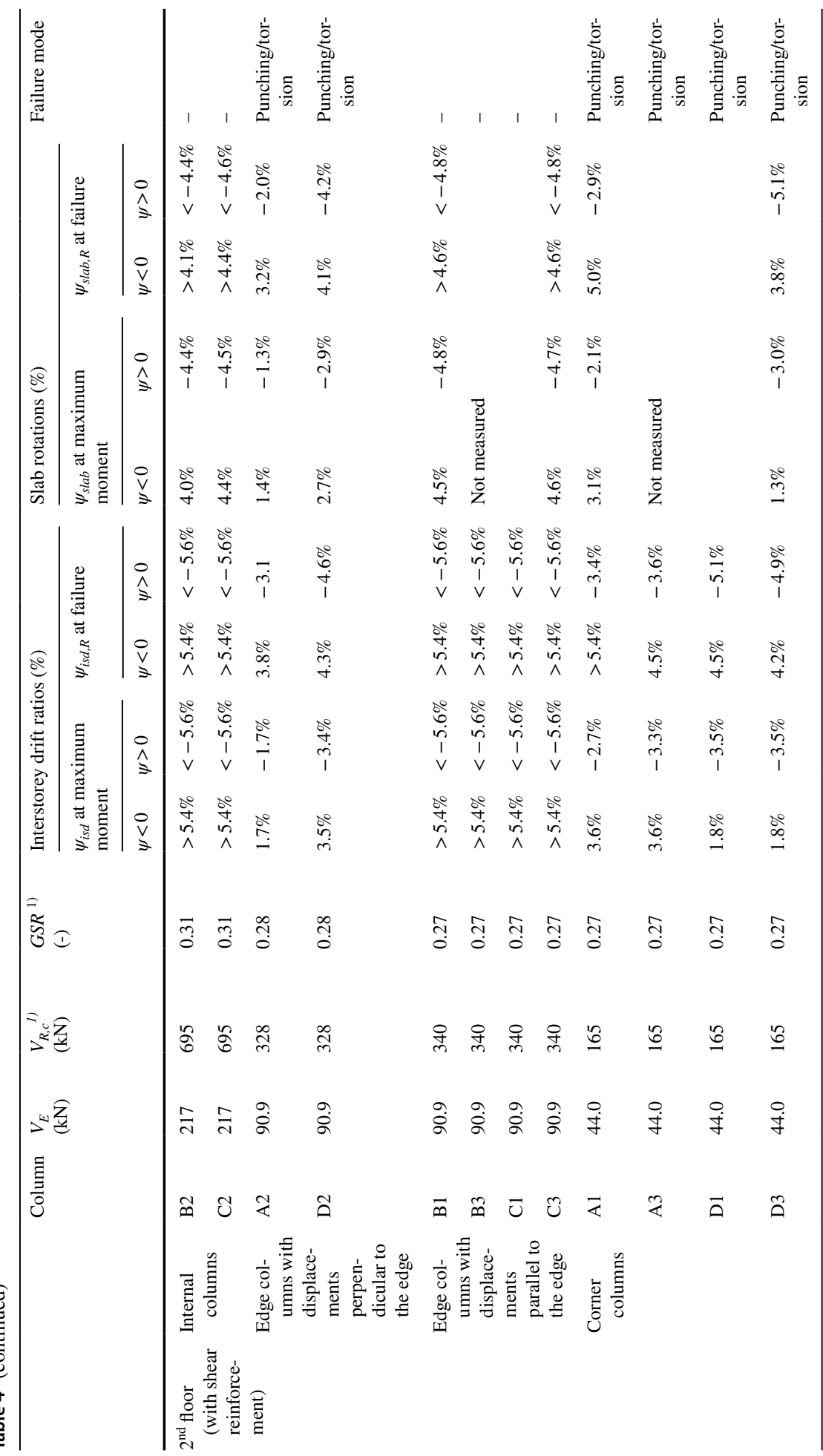




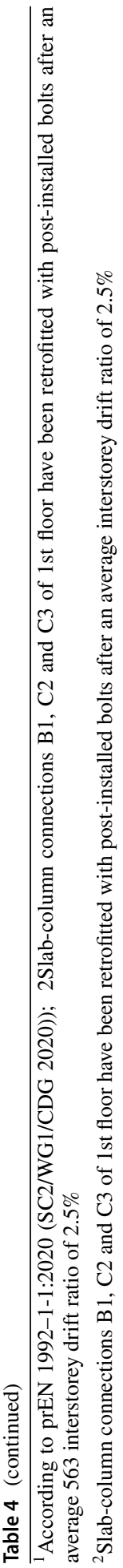

Springer 
order effects are not negligible, in addition to the measured storey shear forces (continuous curves), the shear forces without $2^{\text {nd }}$ order effects (calculated as product of the interstorey drift ratio and the gravity forces) are represented as well (dashed curves). One can observe that after the maximum shear forces attained during the CYC-1 test, and a short softening phase, the forces could be further increased. After reaching the maximum storey shear forces for $\psi_{\text {isd }}$ of $\approx 4.1 \%$ at $1^{\text {st }}$ floor and $\approx 3.5 \%$ at $2^{\text {nd }}$ floor (for exact values, see Table 3 ), a softening behaviour due to $2^{\text {nd }}$ order effects, to the deterioration of the columns bases and to the deterioration of several slab-column connections was observed. At peak shear forces, the $2^{\text {nd }}$ order effects were approximately $11 \%$ of the measured forces for the 1 st floor and approximately $8 \%$ for the $2^{\text {nd }}$ floor. At maximum attained interstorey drift ratios before the test was stopped ( $\psi_{i s d} \approx 6 \%$ ), the $2^{\text {nd }}$ order effects were approximately $20 \%$ and $15 \%$ of the corresponding measured shear forces for the $1^{\text {st }}$ and for the $2^{\text {nd }}$ floor, respectively. If the $2^{\text {nd }}$ order effects are subtracted, the residual resistance at the maximum attained displacements were still between $88.6 \%$ and $91.9 \%$ of the peak values, showing a relatively limited softening behaviour.

Despite the fact that the total shear force at $1^{\text {st }}$ floor is $3 / 2$ of the shear force for the $2^{\text {nd }}$ floor, the interstorey drift ratios at both stories $\psi_{i s d, 1}$ and $\psi_{i s d, 2}$ are similar (difference between 10 and $20 \%$ as shown in Fig. 8). This is due to the higher stiffness of the columns of the $1^{\text {st }}$ floor (effect of clamping in the stiff foundation system, larger axial force in the columns, weaker slab-column connection of the $2^{\text {nd }}$ floor because only one column is connected to the slab).

\subsection{Local behaviour and deformation capacities}

The local behaviours of eight slab-column connections are presented in Fig. 9 (unbalanced moment as a function of the interstorey drift ratio $\psi_{i s d}$ and of the slab rotations $\left.\psi_{\text {slab }}\right)$. The local measurement of the unbalanced moment was made possible by using force transducers inserted in each column that allowed the determination of the internal forces at each node. Similarly, the measurement of rotations $\psi_{\text {slab }}$ was performed using inclinometers directly installed on 8 of the 12 slab-column nodes of each floor (Coronelli et al. 2021, only the connections equipped with inclinometers are presented in Fig. 9). All curves show small differences in the behaviour before and after rotations of about $2.5 \%$. This is related to slight changes in the gravity loads for tests CYC-1 and CYC-2 (black dots refer to the limits between the two tests).

Significant differences in terms of stiffness, maximum resistance, deformation capacity and post-peak behaviour can be observed for the internal, the edge and the corner connections. For the edge connections, the direction of the imposed displacement with respect to the edge also plays a major role (with significantly better behaviour for connections submitted to a displacement parallel to the edge). In the two edge connections A2 and D2 of the $1^{\text {st }}$ floor (edge columns with imposed displacements perpendicular to the edges), the maximum moment was attained for interstorey drift ratios $\psi_{i s d}=1.5-1.8 \%$ followed by a steep softening due to local punching and significant torsional deterioration of the slab edge (for details, see Coronelli et al. 2021). The conventional rotation capacity (defined here as the deformation with $80 \%$ of the maximum moment) of these two connections is $\psi_{i s d, R}=2.0-2.3 \%$ (exact values are given in Fig. 11 and Table 4). The four corner connections (A1, D3 and the unshown connections D1 and A3) also suffered from the same deteriorations related to torsion and out of plane shear in the slab, but with a less steep decrease of the resistance after reaching the maximum flexural resistance (peak moments 
(a)

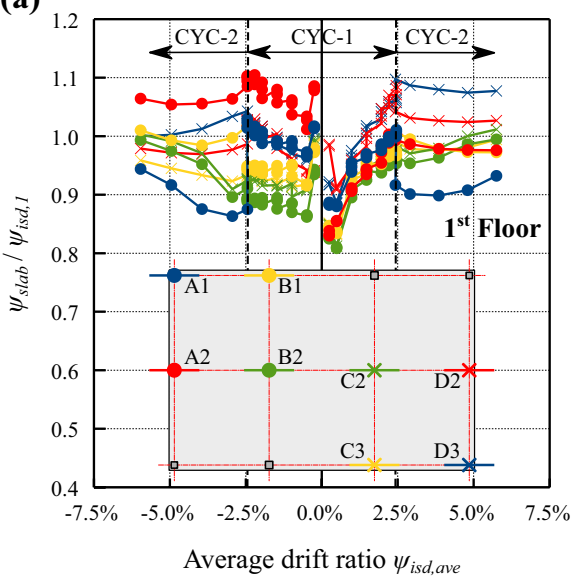

(b)

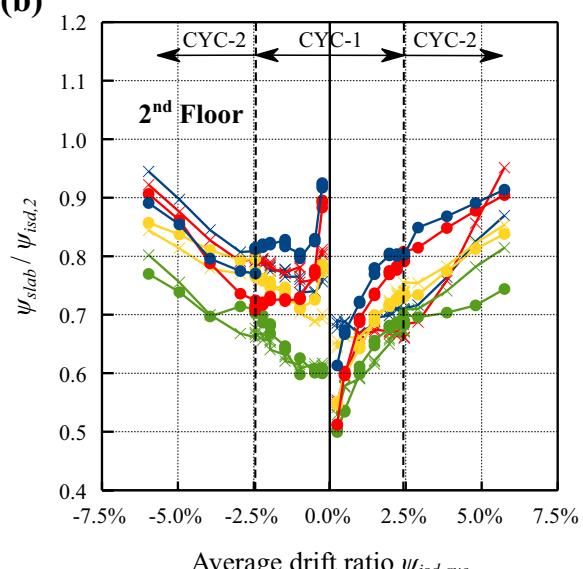

Fig. 10 Ratios between slab rotations $\psi_{\text {slab }}$ and interstorey drift ratios $\psi_{\text {isd }}$ for floor $1 \mathbf{a}$ and $2 \mathbf{b}$ (only peaks of all cycles represented)

were attained for $\psi_{i s d}=1.3-2.1 \%$ and the deformation capacities are $\psi_{i s d, R}=2.4-4.0 \%$ ). The internal slab-column connection B2 of the $1^{\text {st }}$ floor attained the maximum resistance for a significantly higher interstorey drift ratio $\left(\psi_{i s d}=3.1-3.9 \%\right)$ and exhibited a punching failure for $\psi_{i s d, R}=3.9-4.4 \%$ with a significant drop of the flexural resistance thereafter. The internal connection $\mathrm{C} 2$, which was retrofitted with post installed bolts between test CYC-1 and test CYC-2, did not fail and exhibited a hardening behaviour up to rotations $\psi_{\text {slab }}=-4.0 \% /+5.1 \%$ and moderate softening behaviour until the test has been stopped with $\psi_{i s d}=6.0-6.1 \%$. The four edge connections with displacement parallel to the edge (B1, C3 and the unshown connections D1 and A3) did not fail and exhibited a strain hardening behaviour up to interstorey drift ratios $\psi_{\text {slab }} \geq 5.0 \%$ (in connections $\mathrm{C} 1$ and $\mathrm{C} 3$, no softening behaviour was observed before the test was stopped).

The residual resistance to horizontal forces of the failed connections on the first floor (without shear reinforcement) when the test was stopped $\left(\psi_{i s d} \approx 6 \%\right.$ ) was between 12 and $60 \%$ of the peak values for edge connections with imposed displacements perpendicular to the edge, between 41 and $88 \%$ for the corner connections and about $45 \%$ for the internal connections.

The fact that the corner and edge connections with displacement perpendicular to the edge failed for interstorey drifts ratio which were significantly smaller that the deformation capacities of the other connections (approximately 50\%) allowed for a clear redistribution of the internal forces. In addition, the connection which did not fail exhibited a strain hardening behaviour so that they could compensate the softening behaviour of the failed connections. This explains the rather ductile global behaviour with an almost constant resistance to base shear up to an interstorey drift ratio of about $4 \%$ as shown in Fig. $7 \mathrm{~b}$. It is only after the failure of the internal column B2 that a moderate global softening behaviour was observed.

With respect to the second floor with shear reinforcement around the columns, only the two edge connections with displacements perpendicular to the edge (A2 and B2) and the four corner connections (A1, A3, D1 and D3) failed before the test was stopped. As described later, the deformation capacities were not significantly larger than in the floor 


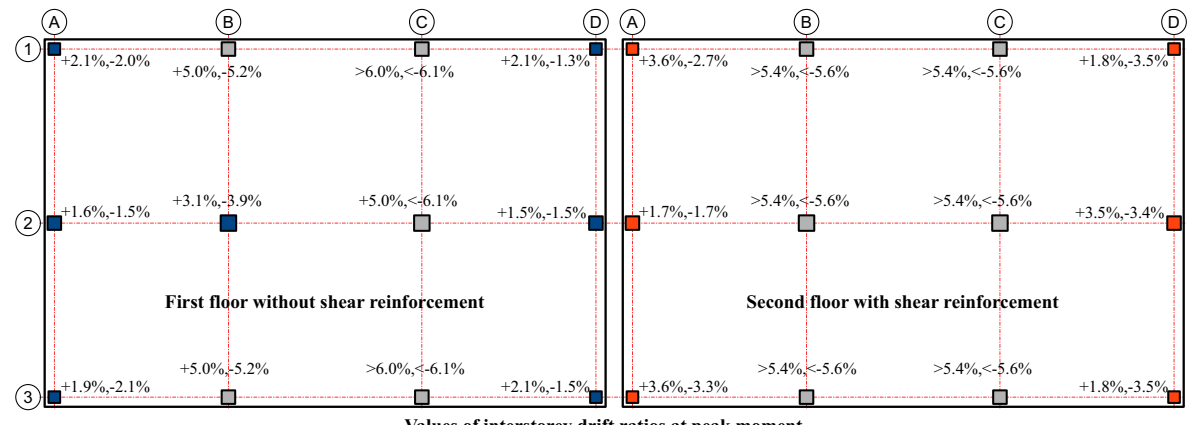

Values of interstorey drift ratios at peak moment

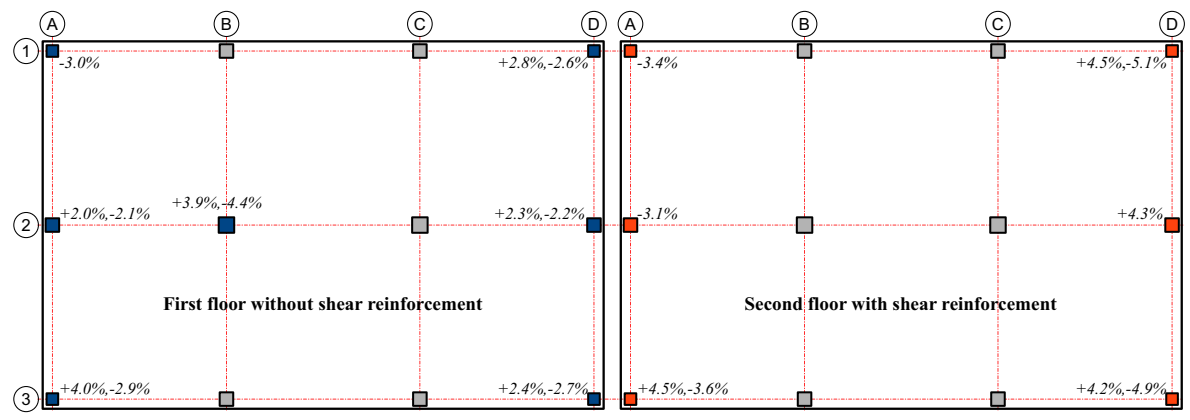

Values of interstorey drift ratios at failure $(80 \%$ of maximum moment $)$

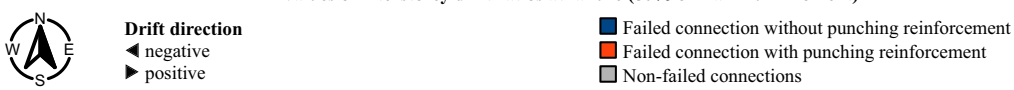

Fig. 11 Interstorey drift ratios at peak moments and at conventional connection failure at $1^{\text {st }}$ and $2^{\text {nd }}$ floor

without shear reinforcement, but the softening behaviour was significantly milder and the residual strength at end of the test were accordingly larger. In this case also, a rather ductile global behaviour was observed due to the significant redistribution of internal forces.

The difference between local rotations $\psi_{\text {slab }}$ (measured with inclinometers) and interstorey drift ratios $\psi_{i s d}$ is depicted in Fig. 9 for both floors. For the $1^{\text {st }}$ floor, the deformability of the columns (see Fig. 1b) is compensated by the clamping of the column bases into the slab foundation, so that relatively large local rotations can be observed (even larger than the interstorey drift ratio, particularly for the corner connections and the edge connections with imposed displacements perpendicular to the edges). Cracking and reinforcement yielding appear in the columns and in the slabs in a similar manner, so that the slab rotations and the interstorey drifts evolve in a similar manner. For the $2^{\text {nd }}$ floor, the fact that the slab-column connections comport only one column reduces the ratio between column and slab stiffness. As a consequence, the slab rotations are typically smaller than the interstorey drift ratios. This is particularly the case for the internal slab-column connections which show significant differences between slab rotations and interstorey drift ratios. With increasing imposed displacements, the stiffness decrease in the slab is more significant than the stiffness losses in the columns (also related to yielding of the slab reinforcement), so that the slab rotations increase more than the interstorey drifts. A similar effect can also be observed as a consequence of local failures, with a pronounced increase of the 


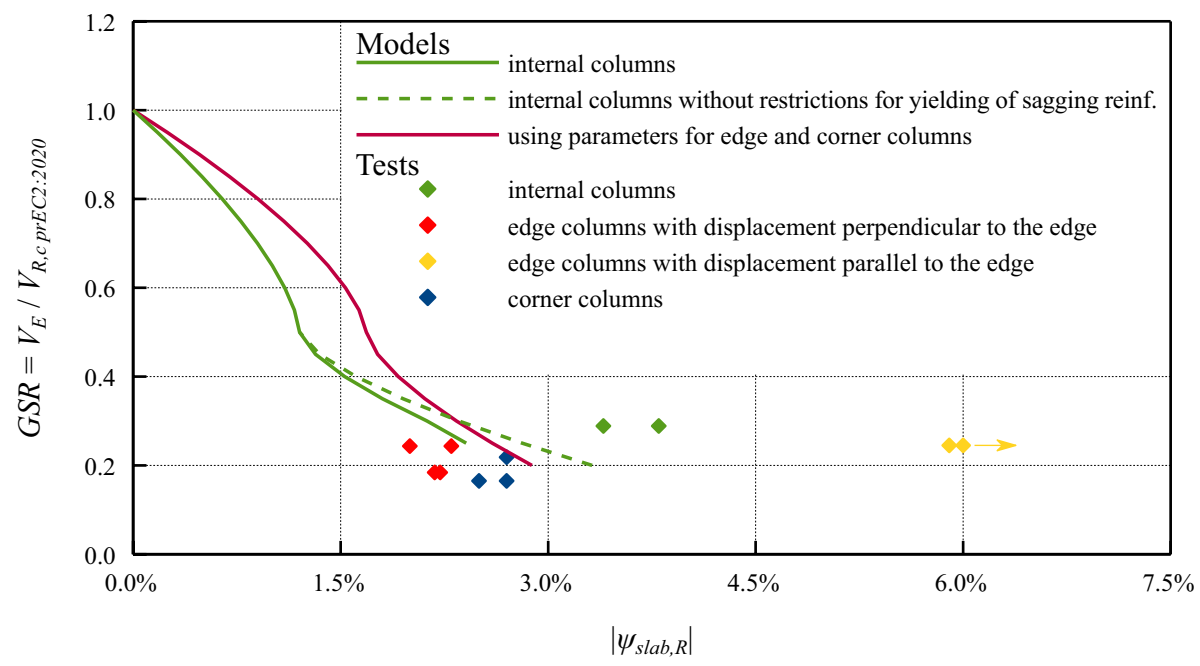

Fig. 12 Comparison of the experimental rotation capacities with the analytical predictions (slab without shear reinforcement)

slab rotation due to the deformation localisation (see for instance the rapid increase of $\psi_{\text {slab }}$ for the edge connections with imposed deformations perpendicular to the edges) Fig. 10.

The deformations at maximum unbalanced moment, as well as the rotation capacities defined as the deformation at the conventional $80 \%$ residual unbalanced moment in the connections are presented in Table 3 for the slabs at $1^{\text {st }}$ floor and at $2^{\text {nd }}$ floor without and with shear reinforcement, respectively. For the first floor, the deformation capacities $\psi_{s l a b, R}$ are of the same order of magnitude as the interstorey drift ratios at failure $\psi_{i s d, R}$ : $\psi_{\text {slab,R }}=2.0-2.3 \%$ for the edge connections with displacement perpendicular to the edge, $\psi_{\text {slab,R }}=2.5-2.7 \%$ for the corner connections, $\psi_{\text {slab,R }}=3.4-3.8 \%$ for the internal connection and $\psi_{\text {slab }, R}>5.9-6.3 \%$ for the edge connections with displacement parallel to the edge.

For the second floor, the differences between slab rotations and interstorey drift ratios are larger. The measured rotation capacities are: $\psi_{s l a b, R}=2.0-4.2 \%$ for the edge connections with displacement perpendicular to the edge and $\psi_{\text {slab,R }}=2.9-5.1 \%$ for the corner connections. The comparison between the two slabs shows that the conventional rotation capacities of the failed connections of the slab with shear reinforcement is not significantly higher than the one of the slab without shear reinforcement. This is probably due to the fact that the failure was initiated by a degradation of the edge region (potentially related to the poor detailing of the anchorage of the flexural reinforcement which is not uncommon in past and current European projects) and less related to a classical shear failure where studs as the shear reinforcement have proven to be very efficient for both gravity and seismic actions (Einpaul et al. (2016), Lips et al. (2012) and Isufi et al. (2019)). With respect to the residual strength after failure, connections with shear reinforcement perform significantly better as described above Fig. 11.

The efficiency of the integrity reinforcement (two bottom bars in each direction, placed in each connection as described above) was assessed both in edge and corner connections, along lines $\mathrm{A}$ and $\mathrm{D}$, and the interior connection B2 after punching. The integrity reinforcement was sufficient to avoid the collapse of the slab since the vertical loads could still be carried after local punching of the connections. 


\subsection{Comparison of the obtained deformation capacities with the proposed model}

Figure 12 shows the comparison of the experimental deformation capacities attained on the $1^{\text {st }}$ floor (without shear reinforcement) with the proposed Eq. (3). It has to be noted that this equation is derived from the mechanical model that was developed for internal slab-column connections and is thus not directly applicable for edge and corner connections. Nevertheless, to allow for a comparison, the deformation capacities according to this approach are calculated also with the parameters of the edge and corner connections (similar parameters for all edge and corner columns, so that only a single curve is presented). Since in edge and corner connections, the reinforcement ratios are smaller than in internal connections, the predicted rotation capacities are larger.

With respect to the internal slab-column connection, the prediction is conservative. This is probably due to the fact that in the prediction, the plastic deformation of the sagging reinforcement was intentionally neglected, whereas the interpretation of the test shows that relatively large plastic deformations of the bottom reinforcement occurred in the column region (see also plastic plateau in the moment-rotation relationship of Fig. 9). This is confirmed by the fact that a reasonable prediction is obtained when restrictions to neglect the plastic deformations of sagging reinforcement are removed (dashed green curve in Fig. 12).

On the contrary, despite the fact that plastic deformations also occurred around corner connections and edge connections with imposed displacements perpendicular to the edge, the observed rotation capacities are smaller than the predictions using the model for internal connections. This observation confirms that the model by Drakatos et al. (2018) and the simplification by Setiawan et al. (2019) are not applicable to these cases. In particular, the significant torsional moments acting in the edge region (and the resulting shear forces along the edges) are not accounted for in both models. It has to be mentioned that the model for internal columns would agree better with the experimental results if the GSR of the latter would be calculated accounting for simplified values of coefficient $\beta_{e}$ proposed by EC2. Nevertheless, this is not justified since coefficient $\beta_{e}$ accounts for the unbalanced moment due to gravity loads and should not be considered in this context.

The case of edge connections with imposed displacements parallel to the edge is again different, with overly conservative predictions according to the model for internal columns.

\section{Discussion}

These observations show that there is a need for a theoretical development of mechanical models for edge and corner connections. The involved parameters should be the same as in the model of Drakatos et al. (2018) for internal columns, but the kinematic assumptions should be adapted and the torsional moments/shear forces in the edge regions should be accounted for.

The present work clearly shows that for both design and research points of view, more attention should be devoted to the deformation capacity of edge and corner columns which show potentially smaller deformation capacities than internal connections. Due to the fact that in practical cases, imposed displacements can occur in all directions (unless very stiff walls run parallel to the edge), the case of edge columns with displacements parallel to the edge is less relevant, whereas the deformation capacity of edge connections with 
significant imposed displacement perpendicular to the edge can become governing for the whole flat slab.

On the other side, the experimental investigation described above has shown that even after the conventional failure (20\% drop of the resistance), a redistribution of internal forces between failed and still resisting connections is possible. This is also due to the fact that the contribution of edge and corner connections is smaller than that of internal connections (less stiff and less resistant) and that all failed connections were still able to carry the gravity actions with a reasonable vertical displacement. This shows the importance of the integrity reinforcement which can be activated after punching preventing the floor collapse (see Fig. 1c) and the collapse of the whole structure, provided that the additional $2^{\text {nd }}$ order effects can be carried by the primary system or/and by the still resisting slab-column connections. This matter also opens the discussion on the definition of failure and of the near collapse limit state. As stated above, the post-punching situation, where the integrity reinforcement is activated after local failure, should be prevented to allow for a reasonable repair after the earthquake, but this principle deserves to be questioned on the basis of an investigation of the practical consequences and a clear definition of the damaged state which can be considered as reparable or not. In addition, the definition of failure as a state with a defined percentage of strength diminution is justified for primary seismic resisting systems, but is questionable for secondary systems.

As described above, the investigated flat-slab frame was designed as a seismic secondary system with a relatively small GSR (also accounting for the partial safety factor as stated in Sect. 3.3, the GSR, see Fig. 12, is smaller than the one that one could expect in a structure which is not overdesigned). For this reason, although the present work provides a step forward in understanding the actual seismic behaviour of flat-slab frames, the findings described above should be validated for the case of larger GSRs. With this respect, it is possible that in slabs with larger gravity loads, more damage would occur after local punching and that the gravity loads could hardly be carried by the integrity reinforcement. Although this paper focuses on the behaviour of flat slabs, the findings can be extrapolated to waffle slabs with a sufficiently large solid portion of slab around the columns.

\section{Conclusions}

This paper presents the development of a closed-form expression derived from mechanical models to predict the deformation capacity of internal slab-column connections without shear reinforcement subjected to imposed horizontal displacements as well as the deformation capacities measured on a full-scale flat slab frame test setup consisting of two floors with and without shear reinforcement and 12 columns (4 internal connections, 12 edge connections and 8 corner connections). The main findings of the paper are:

1) The derived expression to predict the deformation capacity of internal slab-column connections allows to account for all main parameters in a rational manner. The comparison with existing tests shows a fine agreement and confirms that parameters like the size effect (reduced deformation capacity for thicker slabs) can play a major role.

2) The experimental results of the full-scale flat-slab frame test show that a clear distinction should be made between the deformation of the slab (which affects its resistance and defines the deformation capacity of the slab-column connection) and the interstorey drift 
ratio. The slab rotation is typically smaller that the interstorey drift ratio (the column deformation contributes to the deformation capacity of the system), but in some cases the slab rotation can exceed the interstorey drift ratio (in these cases, neglecting the column deformation and comparing the deformation capacity with the interstorey drift ratio can be unconservative).

3) The observed deformation capacities of the slab column connections without shear reinforcement show significant differences between column types and depend on the direction of the imposed displacement. The deformation capacity of edge connections with imposed displacements perpendicular to edge and corner connections are significantly smaller that the observed deformation capacity of internal connections. On the contrary, the deformation capacity of edge connections with imposed displacement parallel to the edge are larger than in internal connections.

4) Similar conclusions can be drawn for the slab with shear reinforcement around the columns, where only edge connections with imposed displacements perpendicular to the edge and corner connections failed. In these cases, larger deformation capacities are attained compared to the slab without shear reinforcement, but to a lesser extent than reported in other works for internal connections.

5) The integrity reinforcement designed according to Eurocode 2 to increase robustness by preventing progressive collapse showed to be effective. With this reinforcement placed in the compression zone of the slab, the gravity loads were still carried after local failures of the slab-column connection.

6) Since in the tested flat slab frame, local and progressive collapses were prevented by the presence of integrity reinforcement, the horizontal shear forces could be redistributed after reaching the deformation capacity of some connections (conventional rotation capacity defined as the deformation with $80 \%$ of the maximum moment) as other connections could still carry additional moments. This redistribution of internal forces allowed to carry a relatively constant base shear force up to a drift ratio of about $6 \%$ when the test has been stopped for safety reasons.

This work confirms the need for additional tests on slabs with realistic dimensions. More research efforts should be also devoted to the investigation of edge and corner slabcolumn connections submitted to imposed lateral displacements. In addition, the deformation capacity of slabs with realistic dimensions and the efficiency of integrity reinforcement should be investigated for higher gravity shear ratios which can be relevant in practice for flat slabs designed as secondary seismic structures for gravity loads where the punching shear resistance is the governing design criterion.

Acknowledgements The experimental campaign was part of the Transnational Access activities of the SERA (Seismology and Earthquake Engineering Research Infrastructure Alliance for Europe) project. This project has received funding from the European Union's Horizon 2020 research and innovation programme under grant agreement No.730900. The authors acknowledge the dedicated and careful work carried out by the Associate Editor and Reviewers whose constructive criticism contributed to a very significant improvement of the quality of the paper. Authors wish to dedicate this work to the memory of their co-author Prof. Ion Radu Pascu, UTCB Bucharest, who passed away on June 10 $0^{\text {th }}, 2021$.

Open Access This article is licensed under a Creative Commons Attribution 4.0 International License, which permits use, sharing, adaptation, distribution and reproduction in any medium or format, as long as you give appropriate credit to the original author(s) and the source, provide a link to the Creative Commons licence, and indicate if changes were made. The images or other third party material in this article are included in the article's Creative Commons licence, unless indicated otherwise in a credit line to the material. If material is not included in the article's Creative Commons licence and your intended use is not 
permitted by statutory regulation or exceeds the permitted use, you will need to obtain permission directly from the copyright holder. To view a copy of this licence, visit http://creativecommons.org/licenses/by/4.0/.

\section{References}

ACI 318 (2019) Building code requirements for structural concrete (ACI 318-19)

Almeida AFO, Inácio MMG, Lúcio VJG, Ramos AP (2016) Punching behaviour of RC flat slabs under reversed horizontal cyclic loading. Eng Struct 117:204-219. https://doi.org/10.1016/j.engstruct.2016. 03.007

Almeida AFO, Alcobia B, Ornelas M, Marreiros R, Ramos AP (2020a) Behaviour of reinforced-concrete flat slabs with stirrups under reversed horizontal cyclic loading. Mag Concr Res 72:339-356. https:// doi.org/10.1680/jmacr.18.00209

Almeida AFO, Ramos AP, Lúcio V, Marreiros R (2020b) Behavior of RC flat slabs with shear bolts under reversed horizontal cyclic loading. Struct Concr 21:501-516. https://doi.org/10.1002/suco.201900128

Benavent-Climent A, Cahís X, Catalán A (2008) Seismic behavior of interior connections in existing waffleflat-plate structures. Eng Struct 30:2510-2516. https://doi.org/10.1016/j.engstruct.2008.02.004

Benavent-Climent A, Cahis X, Catalan A (2009) Reinforced concrete exterior waffle flat plate-column connections subjected to lateral earthquake loading. J Earthq Eng 13:275-292. https://doi.org/10.1080/ 13632460802598453

Benavent-Climent A, Donaire-Avila J, Oliver-Saiz E (2016) Shaking table tests of a reinforced concrete waffle-flat plate structure designed following modern codes: seismic performance and damage evaluation. Earthq Eng Struct Dyn 45:315-336. https://doi.org/10.1002/eqe.2666

Benavent-Climent A, Galé-Lamuela D, Donaire-Avila J (2019) Energy capacity and seismic performance of RC waffle-flat plate structures under two components of far-field ground motions: Shake table tests. Earthq Eng Struct Dyn. https://doi.org/10.1002/eqe.3161

Broms CE (2020) Structural model for interstory drift capacity of flat slabs without shear reinforcement. ACI Struct J 117:45-54

Cao H (1993) Seismic design of slab-column connections. M.Sc. Thesis. University of Calgary

CEN (2002a) EN 1990:2002. Eurocode - Basis of structural design

CEN (2002b) EN 1991-1-1:2002. Eurocode 1: Actions on structures - Part 1-1:General actions - Densities, self-weight, imposed loads for buildings

CEN (2004a) EN 1998-1:2004. Eurocode 8: Design of structures for earthquake resistance - Part 1:General rules, seismic actions and rules for buildings

CEN (2004b) EN 1992-1-1:2004. Eurocode 2: Design of concrete structures - Part 1-1: General rules and rules for buildings

CEN/TC 250/SC 8 (2020) EN1998-1-2 SC8 04-09-2020, Working draft. Eurocode 8: Earthquake resistance design of structures

Cho YS (2009) Structural performance of RC flat plate slab shear-reinforced interior connections under lateral loading. Mag Concr Res 61:155-164. https://doi.org/10.1680/macr.2007.00059

Choi MS, Cho IJ, Han BS, Ahn JM, Shin SW (2007) Experimental study of interior slab-column connections subjected to vertical shear and cyclic moment transfer. Key Eng Mater 348-349:641-644. https:// doi.org/10.4028/www.scientific.net/KEM.348-349.641

Choi J-W, Ali M, Alexander SDB (2009) Behavior of slab-column connections with partially debonded reinforcement under lateral loading. Can J Civ Eng 36:463-472. https://doi.org/10.1139/L09-006

Coelho E, Candeias P, Anamateros G, Zaharia R, Taucer F, Pinto AV (2004) Assessment of the seismic behaviour of RC flat slab building structures. In: 13th world conference on earthquake engineering. Vancouver, B.C., Canada, p Paper No. 2630. https://www.iitk.ac.in/nicee/wcee/article/13_2630.pdf

Coronelli D, Muttoni A, Pascu IR, Ramos AP, Netti T (2020) A state of the art of flat-slab frame tests for gravity and lateral loading. Struct Concr 21:2764-2781. https://doi.org/10.1002/suco.202000305

Coronelli D, Lamperti Tornaghi M, Martinelli L, Molina F, Muttoni A, Pascu IR, Pegon P, Peroni M, Ramos AP, Tsionis G, Netti T (2021) Testing of a full-scale flat slab building for gravity and lateral loads. Eng Struct 243:112551. https://doi.org/10.1016/j.engstruct.2021.112551

CSA (2014) CSA Standard A23.3-14: Design of concrete structures

Dilger WH, Dechka DC, Brown SJ (2005) Slab-Column Connections Under Seismic Actions. ACI Spec Publ 232:127-146

Drakatos IS, Muttoni A, Beyer K (2016) Internal slab-column connections under monotonic and cyclic imposed rotations. Eng Struct 123:501-516. https://doi.org/10.1016/j.engstruct.2016.05.038 
Drakatos IS, Muttoni A, Beyer K (2018) Mechanical model for drift-induced punching of slab-column connections without transverse reinforcement. ACI Struct J 115:463-474

Einpaul J, Brantschen F, Fernández Ruiz M, Muttoni A (2016) Performance of punching shear reinforcement under gravity loading: Influence of type and detailing. ACI Struct J 113:827-838

Emam M, Marzouk H, Hilal MS (1997) Seismic response of slab-column connections constructed with high-strength concrete. ACI Struct J 94:197-205

Fardis MN (2009) Seismic design, assessment and retrofitting of concrete buildings: based on EN-Eurocode 8 (Geotechnical, Geological, and Earthquake Engineering) https://doi.org/10.1007/978-1-4020-9842-0

Farhey DN, Adin MA, Yankelevsky DZ (1993) RC Flat Slab-Column Subassemblages under Lateral Loading. J Struct Eng 119:1903-1916. https://doi.org/10.1061/(ASCE)0733-9445(1993)119:6(1903)

Farhey DN, Adin MA, Yankelevsky DZ (1995) Repaired RC Flat-Slab-Column Subassemblages under Lateral Loading. J Struct Eng 121:1710-1720. https://doi.org/10.1061/(ASCE)0733-9445(1995)121: 11(1710)

Fernández Ruiz M, Mirzaei Y, Muttoni A (2013) Post-Punching Behavior of Flat Slabs. ACI Struct J 110:801-812

fib (2013) fib Model code for concrete structures 2010 Wiley-VCH Verlag GmbH \& Co KGaA, Weinheim, Germany. https://doi.org/10.1002/9783433604090

Joint ACI-ASCE committee 421 (2010) guide to seismic design of punching shear reinforcement in flat plates

Habibi F, Cook WD, Mitchell D (2014) Predicting post-punching shear response of slab-column connections. ACI Struct J 111:123-133

Hawkins NM, Mitchell D, Sheu MS (1974) Cyclic behavior of six reinforced concrete slab-column specimens transferring moment and shear. Seattle, Washington

Hueste MBD, Browning J, Lepage A, Wallace JW (2007) Seismic design criteria for slab-column connections. ACI Struct J 104:448-458

Islam S, Park R (1976) Tests on slab-column connections with shear and unbalanced flexure. J Struct Div 102:549-568

Isufi B, Pinho Ramos A, Lúcio V (2019) Reversed horizontal cyclic loading tests of flat slab specimens with studs as shear reinforcement. Struct Concr 20:330-347. https://doi.org/10.1002/suco.201800128

Isufi B, Rossi M, Ramos AP (2021) Influence of flexural reinforcement on the seismic performance of flat slab - column connections. Eng Struct 242:112583. https://doi.org/10.1016/j.engstruct.2021.112583

Kang TH-K, Wallace JW (2008) Seismic performance of reinforced concrete slab-column connections with thin plate stirrups. ACI Struct J 105:617-625

Kanoh Y, Yoshizaki S (1975) Experiments on slab-column and slab-wall connections of flat plate structures. Concr J 13:7-19

Lips S, Ruiz MF, Muttoni A (2012) Experimental investigation on punching strength and deformation capacity of shear-reinforced slabs. ACI Struct J 109:889-900

Marzouk H, Osman M, Hussein A (2001) Cyclic loading of high-strength lightweight concrete slabs. ACI Struct J 98:207-214

Megally S, Ghali A (2000) Punching shear design of earthquake-resistant slab- column connections. ACI Structral J 97:720-730

Moehle JP (1996) Seismic design considerations for flat-plate construction. ACI Spec Publ 162:1-34

Morrison DG, Hirasawa I, Sozen MA (1983) Lateral-load tests of R/C slab-column connections. J Struct Eng 109:2698-2714. https://doi.org/10.1061/(ASCE)0733-9445(1983)109:11(2698)

Muttoni A (2008) Punching shear strength of reinforced concrete slabs. ACI Structral J 105:440-450

Muttoni A, Fernández Ruiz M, Simões JT (2018) The theoretical principles of the critical shear crack theory for punching shear failures and derivation of consistent closed-form design expressions. Struct Concr 19:174-190. https://doi.org/10.1002/suco.201700088

Pan A, Moehle JP (1989) Lateral displacement ductility of reinforced concrete flat plates. ACI Struct J $86: 250-258$

Park H-G, Kim Y-N, Song J-G, Kang S-M (2012) Lattice shear reinforcement for enhancement of slab-column connections. J Struct Eng 138:425-437. https://doi.org/10.1061/(ASCE)ST.1943-541X.0000484

Park YM, Han SW, Ryu JH (2007) Comparison of seismic behaviors of interior joints in PT and RC flat plate systems. In: Key Engineering Materials. pp 741-745. https://doi.org/10.4028/www.scientific.net/ KEM.348-349.741

Pinto A, Taucer F, Dimova S (2007) Pre-normative research needs to achieve improved design guidelines for seismic protection in the EU. https://eurocodes.jrc.ec.europa.eu/doc/EUR22858EN.pdf

Ramos A, Marreiros R, Almeida A, Isufi B, Inácio M (2017) Punching of flat slabs under reversed horizontal cyclic loading. In: Ospina C, Mitchell D, Muttoni A (eds) ACI SPecial Publication 315. ACI, fib, pp 253-272 
Robertson I, Johnson G (2006) Cyclic lateral loading of nonductile slab-column connections. ACI Struct J 103:356-364

Robertson IN, Kawai T, Lee J, Enomoto B (2002) Cyclic testing of slab-column connections with shear reinforcement. ACI Struct J 99:605-613

Robertson IN (1990) Seismic response of connections in indeterminate flat-slab subassemblies. Ph.D. Thesis. Rice University

SC2/WG1/CDG (2020) Updated Draft prEN 1992-1-1-D7 (Rev. 7) 2020-11-16. Eurocode 2: Design of concrete structures - Part 1-1: General rules - Rules for buildings, bridges and civil engineering structures

Setiawan A, Vollum RL, Macorini L (2019) Numerical and analytical investigation of internal slab-column connections subject to cyclic loading. Eng Struct 184:535-554. https://doi.org/10.1016/j.engstruct. 2019.01.089

Song JK, Kim J, Song HB, Song JW (2012) Effective punching shear and moment capacity of flat platecolumn connection with shear reinforcements for lateral loading. Int J Concr Struct Mater 6:19-29. https://doi.org/10.1007/s40069-012-0002-3

Spence R, Lopes M, Bisch P, Plumier A, Dolce M (2007) Earthquake risk reduction in the European Union. Proposal for a European earthquake risk reduction programme - a discussion document (following Lisbon Workshop 2005). Lisbon

Stark A, Binici B, Bayrak O (2005) Seismic upgrade of reinforced concrete slab-column connections using carbon fiber-reinforced polymers. ACI Struct J 102:324-333

Tian Y, Jirsa JO, Bayrak O, Widianto AJF (2008) Behavior of slab-column connections of existing flat-plate structures. ACI Struct J 105:561-569

Wey EH, Durrani AJ (1992) Seismic response of interior slab-column connections with shear capitals. ACI Struct J 89:682-691

Zee H, Moehle J (1984) Behavior of Interior and Exterior Flat Plate Connections subjected to Inelastic Load Reversals. Rep No UCB/EERC-84/07 121

Zhou Y, Hueste MBD (2017) Review of test data for interior slab-column connections with moment transfer. In: Ospina C, Mitchell D, Muttoni A (eds) ACI SPecial Publication 315. ACI, fib, pp 141-166

Publisher's Note Springer Nature remains neutral with regard to jurisdictional claims in published maps and institutional affiliations.

\section{Authors and Affiliations}

A. Muttoni ${ }^{1}$ - D. Coronelli ${ }^{2} \cdot$ M. Lamperti Tornaghi ${ }^{3}$ D $\cdot$ L. Martinelli $^{2} \cdot$ I. R. Pascu . $^{4}$ A. Pinho Ramos ${ }^{5} \cdot$ G. Tsionis ${ }^{3} \cdot$ P. Bamonte ${ }^{2} \cdot$ B. Isufi ${ }^{5}$ A. Setiawan ${ }^{1}$

1 École Polytechnique Fédérale de Lausanne, 1015 Lausanne, Switzerland

2 Politecnico di Milano, Department of Civil and Environmental Engineering, 20133 Milan, Italy

3 European Commission, Joint Research Centre (JRC), 21027 Ispra, Italy

4 Universitatea Tehnică de Construcţii Bucureşti, 020396 București, Romania

5 Universidade Nova de Lisboa, Department of Civil Engineering, 2829-516 Caparica, Portugal 